\title{
Meristemas: fontes de juventude e plasticidade no desenvolvimento vegetal
}

\author{
Maria Aurineide Rodrigues ${ }^{1}$ e Gilberto Barbante Kerbauy ${ }^{1,2}$
}

Recebido: 30.07.2009; aceito: 06.11.2009

\begin{abstract}
Meristems: Sources of youth and plasticity in plant development). Plants are sessile organisms which are able to overcome environmental adversities due to their exceptional developmental plasticity, an attribute mainly conferred by the meristems. In these specialized tissues are found the self-renewing stem cells that maintain the meristematic identity, as well as the derived cellular progenies involved in the formation of several tissues and new organs. The diversity of cellular identities in both apical meristems and surrounding tissues is tightly controlled by positional exchange of intercellular signals such as transcription factors and plant hormones. The various cues acting on meristematic activity regulation are integrated in signaling networks that have been discovered in plant models, thereby, improving our understanding in this field of research. Currently, increasing interest has been observed in comparative analyses regarding the conservation of the developmental mechanisms controlling the meristematic activity among different plant species.
\end{abstract}

Key words: hormones, plant growth, stem cells, transcription factors

RESUMO - (Meristemas: Fontes de juventude e plasticidade no desenvolvimento vegetal). As plantas são organismos sésseis capazes de adequarem-se às diferentes condições ambientais por apresentarem uma considerável plasticidade de desenvolvimento, conferida, principalmente, pelos meristemas. Nestes tecidos encontram-se as células-tronco capazes de se auto-perpetuarem, mantendo a identidade meristemática, bem como as células derivadas de sua atividade, estas comprometidas com a formação dos diferentes tecidos e órgãos. As identidades das populações celulares nos meristemas apicais e tecidos circunvizinhos são rigorosamente controladas por trocas de informações posicionais através de moléculas sinalizadoras como os fatores de transcrição e os hormônios vegetais. Os diversos sinais reguladores da atividade meristemática encontram-se integrados em vias sinalizadoras que vêm sendo desvendadas por meio de estudos realizados em algumas plantas-modelo, proporcionando um grande avanço no conhecimento nesta área da pesquisa. Atualmente, observa-se um interesse crescente em se analisar comparativamente o grau de conservação dos mecanismos controladores da atividade meristemática entre as espécies vegetais.

Palavras-chave: células-tronco, crescimento vegetal, hormônios, fatores de transcrição

\section{Introdução}

A natureza séssil das plantas impõe uma série de desafios à sobrevivência, uma vez que as torna altamente susceptíveis às variações e adversidades ambientais (Birnbaum \& Alvarado 2008). A questão que imediatamente se coloca é: Como as plantas conseguem ajustar tão eficientemente o desenvolvimento sem sair do lugar, mesmo quando sujeitas a diversas e intensas variações ambientais?

A resposta desta pergunta está relacionada ao fato das plantas possuírem um padrão de desenvolvimento distinto da maioria dos animais, uma vez que elas podem manter a capacidade de gerar novos tecidos e órgãos de maneira recorrente durante a vida, caracterizando o tipo de crescimento denominado aberto ou indeterminado (Srivastava
2002, Vernoux \& Benfey 2005). Por outro lado, a grande maioria dos animais apresenta um padrão de crescimento fechado ou determinado, ou seja, neles a definição de quase todos os tecidos e órgãos especializados ocorre durante a embriogênese, sendo o desenvolvimento pós-embrionário caracterizado, prioritariamente, pelo aumento de tamanho e do número de células (Srivastava 2002, Baurle \& Laux 2003). O arranjo indeterminado do corpo das plantas, no qual o número de órgãos não é pré-definido e há a capacidade de crescer e se desenvolver de maneira modular durante a vida pós-embrionária, confere aos vegetais uma maior plasticidade de respostas às variações ambientais, tanto no nível fisiológico quanto morfológico (Dinneny \& Benfey 2008), desempenhando papel "compensatório" à sua natureza séssil.

1. Universidade de São Paulo, Instituto de Biociências, Departamento de Botânica, Caixa-Postal 11461, 05422-970 São Paulo, SP, Brasil

2. Autor para correspondência: gbtkerba@ib.usp.br 
Do acima exposto, levanta-se um segundo questionamento: Qual o mecanismo celular que proporciona às plantas a capacidade de formar novos tecidos e órgãos durante o desenvolvimento pós-embrionário? Essa conspícua flexibilidade no desenvolvimento das plantas é protagonizada, em última análise, por pequenos grupos celulares - os meristemas -, que funcionam como verdadeiras fontes de células mantenedoras de características juvenis e da potencialidade para diferenciação em diversos tecidos especializados durante o desenvolvimento pósembrionário das plantas (Dinneny \& Benfey 2008). Tal universo microscópico, que guarda boa parte dos segredos para a incrível capacidade apresentada pelos vegetais de crescer e de se desenvolver durante toda a vida, tem fascinado gerações de pesquisadores, os quais vêm acrescentando valiosas contribuições para um entendimento mais consistente sobre o desenvolvimento vegetal.

Nesta revisão pretende-se compilar, resumidamente, os principais avanços resultantes das pesquisas até hoje realizadas sobre a biologia meristemática, com ênfase nos mecanismos regulatórios altamente refinados que vêm sendo elucidados como fundamentais para o funcionamento e manutenção dos meristemas. Juntamente a esses aspectos, serão apresentados e discutidos alguns conceitos e a própria terminologia hoje utilizada nos estudos dos meristemas. Finalmente, será discutida a abrangência dos mecanismos de controle meristemático descobertos nas principais plantas-modelo em relação a outros sistemas vegetais.

\section{Avanço no conhecimento sobre os meristemas}

As primeiras informações conhecidas sobre os meristemas datam da segunda metade do século XVIII, quando Caspar Friedrich Wolff estabeleceu em sua Theoria Generationis (1759) que o ápice caulinar seria uma estrutura central da parte aérea da planta, responsável pela formação de novas folhas e tecidos caulinares (Steeves 2006). Entretanto, o termo meristema foi proposto por Carl Wilhelm von Nageli em 1858, um século mais tarde, para designar os conjuntos de células responsáveis pela origem de "órgãos inteiros", procurando com isso distinguir as células apicais por ele relatadas, daquelas já reconhecidas como componentes do câmbio; uma vez que nessa época o termo "câmbio" era utilizado de modo genérico para ambos os grupos celulares (Scofield \& Murray 2006).
Após as primeiras observações e definições das características elementares dos meristemas, diversas análises sobre a organização estrutural destes grupos de células foram conduzidas desde a metade do século XIX até meados do século XX, marcadas pela observação tecidual por meio de microscopia óptica. No período seguinte, entre as décadas de 1940 e 1970, foram feitas muitas descobertas interessantes sobre os mecanismos de funcionamento dos meristemas por meio de análises quiméricas, micro-cirúrgicas e por marcações com radioisótopos (Sussex 2006).

Estas duas fases iniciais da pesquisa meristemática possibilitaram informações relativamente consistentes sobre a organização estrutural desses grupos de células, bem como ajudaram a estabelecer os conceitos gerais sobre a maneira pela qual os meristemas influenciam o crescimento aberto das plantas vasculares. Durante esse mesmo período, foram identificados e descritos diferentes tipos de meristemas na parte aérea e no sistema radicular das plantas, com destaque para os dois meristemas primários definidos durante a embriogênese: o meristema apical caulinar e o meristema apical radicular. Além destes, também foi verificado o estabelecimento de outros meristemas de origem pós-embrionária, tais como meristemas axilares do caule, meristemas formadores de raízes laterais, entre outros (Srivastava 2002, Scofield \& Murray 2006).

Não obstante as diferentes origens, assim como os destinos das células derivadas de suas atividades, todos os meristemas possuem certas características em comum. Os meristemas foram reconhecidos como tecidos proliferativos presentes em regiões específicas do corpo vegetal em crescimento, os quais geram continuamente novas células para a formação de tecidos e órgãos (Beveridge et al.2007). Dessa forma, o crescimento vegetal foi considerado dependente das regiões meristemáticas, e ocorreria em duas fases: uma primeira fase proliferativa com aumento da massa celular tanto por divisões celulares nos meristemas quanto pela síntese de macromoléculas; e uma segunda fase onde as células cessam a proliferação e passam a se expandir, aumentando individualmente em volume. As células meristemáticas cessam suas divisões mitóticas à medida que são liberadas dos meristemas para, então, serem incorporadas aos tecidos de órgãos específicos, proporcionando a diferenciação e o crescimento de caules e ramos, a formação de folhas e flores, bem como a formação e contínuo desenvolvimento do sistema radicular (Singh \& Bhalla 2006, Bögre et al. 2008). 
A partir de meados dos anos 1980, o advento de novas tecnologias acopladas à utilização intensa de plantas-modelo, permitiu a realização de análises sofisticadas do ponto de vista celular, genético e molecular, possibilitando um avanço substancial no entendimento da organização e do funcionamento dos meristemas, principalmente dos apicais (Steeves 2006). Juntamente às novas informações obtidas nos últimos anos, deu-se a incorporação de novos conceitos, idéias e termos, nessa área do conhecimento, os quais não raramente foram originados de diferentes áreas da pesquisa biológica, principalmente animal.

\section{Novos conceitos e terminologias no estudo meristemático}

Terminologias e conceitos recentemente incorporados ao vocabulário básico nos estudos meristemáticos ainda geram algumas dúvidas. Isso se deve, principalmente, ao volume considerável de informações inéditas provenientes de pesquisas sobre o desenvolvimento vegetal nos últimos anos, principalmente na área molecular. Além disso, este cenário foi acompanhado por uma grande velocidade na divulgação dos resultados gerados por especialistas nos mais diversos ramos da pesquisa biológica, não havendo uma uniformização prévia dos termos e interpretações publicados.

Portanto, nesse momento observa-se uma preocupação crescente por parte de especialistas envolvidos em estudos de meristemas no sentido de minimizar as divergências terminológicas e/ou conceituais existentes neste campo da pesquisa. Tal panorama tem levado, por exemplo, à existência ligeiramente comum de revisões sobre o tema, nas quais os próprios autores procuram apresentar as definições em que se pautaram para a discussão apresentada (Tucker \& Laux 2007, Scheres 2007, Beveridge et al. 2007), ou até mesmo revisões que trazem a proposta de discutir possíveis interpretações para os novos termos empregados na biologia meristemática (Laux 2003, Ivanov 2004). Sob esse enfoque, a seguir será apresentada uma compilação dos principais conceitos e nomenclaturas que vêm sendo introduzidas nos estudos de meristemas.

Potencialidade das células meristemáticas para rotas específicas de desenvolvimento - O grau de plasticidade celular para as diferentes rotas de desenvolvimento foi primeiramente definido para as células animais, as quais foram classificadas como unipotentes, multipotentes, pluripotentes e totipotentes (Can 2008). Este sistema classificatório, posteriormente adotado também para as células vegetais, foi estabelecido com base nos seguintes parâmetros: (1) células unipotentes seriam aquelas capazes de originar apenas um tipo específico de célula ou tecido; (2) células multipotentes seriam aquelas com habilidade de originar mais de um tipo de célula no corpo do organismo; (3) células pluripotentes, por sua vez, possuiriam a habilidade de originar a maior parte dos diferentes tipos celulares que compõe o organismo; e, finalmente, (4) as células totipotentes seriam aquelas aptas a originar todos os tipos celulares que formam o corpo do organismo (Verdeil et al. 2007).

Apesar das células animais terem sido as primeiras a serem classificadas conforme indicado acima, os conceitos de plasticidade e totipotência celular foram introduzidos anteriormente por meio de estudos com células vegetais. O termo totipotência foi proposto em 1902, pelo ilustre botânico Gottlieb Haberlandt, para descrever a potencialidade intrínseca de uma célula vegetal para originar uma planta completa. De acordo com Haberlandt, "seria possível a obtenção de embriões artificiais a partir da cultura de células somáticas" (Haberlandt 1902). Nas tentativas não sucedidas de demonstrar experimentalmente a totipotencialidade das células vegetais, Haberlandt acabou estabelecendo, de forma consistente, os princípios norteadores da técnica da cultura de células, tecidos e órgãos vegetais, hoje amplamente utilizada (Hoxtermann 1997). Todavia, a totipotência de células vegetais viria a ser demonstrada experimentalmente cerca de 50 anos mais tarde, quando Steward e colaboradores clonaram uma planta de cenoura a partir de embrião obtido de células somáticas cultivadas in vitro (Steward et al. 1958).

Diferentemente das células de uma planta adulta, as quais podem expressar a totipotencialidade sob condições in vitro, as células de mamíferos parecem perder as características totipotentes já no estágio embrionário pós-zigótico, composto por apenas oito células (Burdon et al. 2002). Dessa forma, a plasticidade celular em mamíferos diminui à medida que o desenvolvimento embrionário avança, resultando na formação de células multipotentes como, por exemplo, as que compõem o tecido hematopoiético da medula óssea, especializadas em originar os diferentes tipos de células sanguíneas (Orkin 2000).

Durante a década passada observou-se um avanço considerável no entendimento sobre o controle molecular da potencialidade celular de mamíferos 
devido, especialmente, ao aprimoramento da cultura in vitro de células somáticas, o qual foi acompanhado com grande entusiasmo frente às possibilidades de aplicação destes conhecimentos na medicina regenerativa. Paradoxalmente, apesar da totipotencialidade das células vegetais sob cultivo in vitro ter sido reconhecida há cerca de meio século sendo, inclusive, amplamente utilizada na micropropagação de plantas de interesse agrícola, conhece-se muito pouco sobre as bases moleculares que conferem essa habilidade às mesmas (Verdeil et al. 2007). Tanto assim, que a embriogênese somática em plantas foi recentemente incluída entre os 25 tópicos considerados mais relevantes e ainda pouco entendidos em todas as áreas da Ciência (Vogel 2005).

A manifestação da totipotencialidade vegetal na embriogênese somática envolve a desdiferenciação das células somáticas, por meio da qual são alterados os perfis de transcrição gênica e de tradução protéica pré-existentes nas células especializadas, permitindo o estabelecimento de um novo programa de desenvolvimento. Isso se dá porque os destinos celulares dependem de informações espacialmente definidas no corpo da planta, as quais são originadas de acordo com as condições ambientais e o estágio de desenvolvimento vegetal. Assim, a expressão da totipotencialidade das células vegetais é geralmente induzida sob condições específicas de cultivo in vitro, as quais proporcionam a alteração do status quo das células somáticas por meio da formação de um calo constituído por células totipotentes e, portanto, competentes para embriogênese somática (Steward et al. 1958, Fehér et al. 2003, Atta et al. 2009).

Mesmo estando a totipotência das células vegetais geralmente relacionada às condições específicas de cultivo in vitro supracitadas, ainda são encontrados trabalhos recentes que empregam esta terminologia, de maneira equivocada, para referir-se à potencialidade de células meristemáticas, como exemplificado a seguir: "As células que estão posicionadas na região central do meristema apical caulinar são as fontes de células totipotentes que servem como precursoras para a formação de novos órgãos da parte aérea da planta" (Fiers et al. 2007). Na realidade, apesar das células contidas nos meristemas apicais possuírem a capacidade de originar os diferentes tipos celulares responsáveis pela formação dos tecidos e órgãos envolvidos no desenvolvimento vegetal, elas não apresentam a capacidade de formar um organismo completo (ou seja, um embrião) quando mantidas in situ, razão pela qual as células meristemáticas têm sido consideradas de natureza pluripotente quando contextualizadas no corpo vegetal (Singh \& Bhalla 2006, Verdeil et al. 2007).

Iniciais meristemáticas e células-tronco nas plantas - Dentre todos os novos termos empregados para descrever as propriedades meristemáticas, possivelmente, o de "células-tronco" seja o mais polêmico. Essencialmente, as células-tronco, ou células primordiais (do inglês stem cells), representam tipos celulares com habilidade de se dividir, mantendo seu próprio grupo de células morfologicamente indiferenciadas, ao passo que também proporcionam a formação de células derivadas que entram numa rota específica de diferenciação e formação de novos tecidos e órgãos (Tucker \& Laux 2007, Dello-Ioio et al. 2008). Estes atributos foram primeiramente relatados para certas células animais, porém, a mesma designação foi adotada também para alguns tipos celulares vegetais localizados nos meristemas (Singh \& Bhalla 2006, Verdeil el al. 2007).

Mesmo que aceita a existência de células-tronco tanto em animais quanto em plantas (Sablowski 2004), sabe-se que estes grupos celulares apresentam diferenças consideráveis na forma pela qual participam no desenvolvimento dos indivíduos de seus respectivos reinos. A maioria dos animais utiliza as células-tronco principalmente para compensar perdas celulares durante o desenvolvimento pós-embrionário (Vernoux $\&$ Benfey 2005). De maneira curiosa, a longevidade de muitos invertebrados encontra-se associada à manutenção e à regulação de células-tronco em tecidos somáticos durante a vida pós-embrionária, uma vez que elas permitem a reposição das células diferenciadas mortas, assegurando, consequentemente, a sobrevivência de tais organismos após injúrias físicas (Birnbaum \& Alvarado 2008). Nas plantas, por outro lado, por serem organismos de crescimento aberto, as células-tronco são produzidas e utilizadas como fonte contínua de células envolvidas na formatação de novas estruturas durante toda a vida. A presença das célulastronco nos meristemas permite o desenvolvimento recorrente de novos órgãos, ocasionando modificações constantes na forma da planta, mesmo tendo esta se iniciado a partir de um embrião com organização tecidual rudimentar (Vernoux \& Benfey 2005).

Sendo assim, os meristemas têm sido reconhecidos como as regiões geradoras e mantenedoras das células-tronco nas plantas intactas, tendo em vista que atendem às premissas de divisão celular 
assimétrica (responsável pela diversidade de tipos celulares) acoplada à auto-proliferação (Weigel \& Jürgens 2002, Knoblich 2008). Desse modo, as células totipotentes cultivadas in vitro foram excluídas dessa classificação por Laux (2003), uma vez que elas não exibem adequadamente as características supracitadas. No entanto, Verdeil et al. (2007) propuseram que o conceito de células-tronco deveria ser estendido às células somáticas embriogênicas obtidas in vitro, as quais, segundo tais autores, deveriam ser denominadas de "células-tronco totipotentes isoladas". Além destas divergências sobre quais tipos de células vegetais deveriam receber a denominação de células-tronco em um contexto mais amplo, também se observa certa discordância sobre qual grupo de células pluripotentes dentro dos meristemas deveria receber tal nomenclatura.

Em termos de atividade mitótica, os meristemas apicais possuem, basicamente, dois sítios com diferentes taxas de divisão celular, sendo um deles ocupado pelas células denominadas de "iniciais estruturais" (que se dividem com menor freqüência e encontradas nos centros geradores de células meristemáticas - o centro quiescente nas raízes e o centro organizador nos caules); na segunda região, por sua vez, encontram-se as células chamadas de "iniciais funcionais", as quais apresentam taxa mitótica mais elevada e encontram-se ao redor dos centros geradores de células meristemáticas (Barlow 1997, Jiang \& Feldman 2005). Alguns autores consideram as células iniciais estruturais como células-tronco (Carraro et al. 2006, Fiers et al. 2007, Gómez-Mena \& Sablowski 2008), enquanto outros advogam que as iniciais funcionais se enquadrariam de maneira mais adequada como verdadeiras células-tronco (Weigel \& Jürgens 2002, Sabatini et al. 2003).

Alguma luz foi lançada sobre esta questão por Ivanov (2004) na sua extensa compilação comparativa das características conhecidas para estas duas populações de células iniciais, baseando-se nos seguintes critérios definidos por Potten \& Loeffler (1997) para classificação de células-tronco: (1) células "não diferenciadas", ou seja, destituídas de marcadores de diferenciação tecidual; (2) habilidade de proliferação; (3) capacidade de auto-manutenção da população celular; (4) habilidade para produzir numerosas descendências celulares funcionalmente diferenciadas; (5) habilidade de regenerar tecidos após injúria; (6) uso flexível destas características.

Segundo estes critérios, Ivanov (2004) concluiu que as células iniciais estruturais (ou seja, aquelas localizadas nos centros geradores de iniciais meristemáticas) seriam as que reuniriam um maior número de atributos de células-tronco. Dessa forma, a maioria dos trabalhos atuais considera as células iniciais estruturais, juntamente com as iniciais imediatamente derivadas de sua divisão mitótica, como as verdadeiras células-tronco nos meristemas apicais.

Regiões meristemáticas como nichos celulares ou microambientes - Os estudos pioneiros com meristemas descreveram estes tecidos como possuidores de aspecto celular homogêneo. Entretanto, a partir de meados do século XIX, estudos mais pormenorizados indicaram que os mesmos eram constituídos de regiões histológicas distintas (Sussex 2006). Atualmente, sabe-se que além de terem regiões histologicamente distintas, estas também diferem funcionalmente entre si, e suas funções são determinadas por padrões específicos de sinais endógenos (Scofield \& Murray 2006). Dessa forma, as funções essenciais das célulastronco nas plantas dependem, assim como nos animais, do posicionamento destas em uma região altamente regulada por sinais endógenos presentes. Estas regiões meristemáticas têm recebido designações diversas, oriundas da terminologia própria da Ecologia, tais como um "microambiente" propício para a manutenção do "nicho das células-tronco" (Aida et al. 2004, Laux 2003, Dinneny \& Benfey 2008).

Sendo assim, o conceito de nicho de célulastronco implica no reconhecimento de que estas células adquirem ou expressam as características típicas não por possuírem propriedades celulares específicas pré-existentes, mas porque se encontram em um "microambiente" que define o nicho meristemático destas células (Jiang \& Feldman 2005). A região onde as células-tronco estão localizadas nos meristemas também tem sido denominada como o "hábitat" das células-tronco; neste local ocorre o estabelecimento de um sistema complexo e bem integrado de sinalização intercelular necessário para a manutenção deste grupo de células. Assim, esse conjunto de características estabelecido pela inter-relação celular em seu "hábitat" possibilita a formação e manutenção do "nicho" das células-tronco nos meristemas (Tucker \& Laux 2007).

Comunicação intercelular no interior dos meristemas - A comunicação intercelular nos meristemas desempenha papel essencial no controle de sua organização e funcionamento, uma vez que este sistema permite a regulação coordenada dos diferentes sinais que participam da manutenção do nicho das células-tronco, assim como na especificação 
dos destinos de suas células descendentes (Miwa et al.2009). As células meristemáticas possuem também fortes interações com os tecidos localizados nos seus arredores, cuja integração é fundamental para o controle rigoroso da identidade das células-tronco (Stahl \& Simon 2005, Verdeil et al. 2007).

Nas plantas, a comunicação entre as células é realizada por meio do trânsito de moléculas como nutrientes, hormônios e proteínas, as quais, freqüentemente, desempenham papel sinalizador em importantes processos celulares. Esta comunicação pode ocorrer por duas vias: transporte das moléculas célula-a-célula, via espaços intercelulares, ou por meio de plasmodesmas (Carraro et al. 2006). As células meristemáticas e suas vizinhas comunicamse por meio de plasmodesmas (Kurata 2005), os quais permitem a formação de domínios simplásticos essenciais à circulação de um grande número de moléculas sinalizadoras (Gisel et al. 1999, Lucas \& Lee 2004).

Foi verificada intensa correlação entre o grau de comunicação celular e a potencialidade das células vegetais para seguir diferentes rotas de desenvolvimento. Por exemplo, o isolamento físico de células somáticas diferenciadas parece facilitar a reprogramação de suas funções genômicas e celulares na aquisição da totipotência e da competência para a embriogênese. Estes eventos estiveram associados ao aumento do isolamento físico e fisiológico destas células devido ao espessamento da parede celular e à ausência, ou redução, do número de plasmodesmas (Dubois et al. 1990, Verdeil et al.2001). Por outro lado, as rotas simplásticas estabelecidas por plasmodesmas nos meristemas de plantas intactas permitem a passagem de diversos sinais específicos que parecem assegurar a sua pluripotencialidade celular. Dentre os sinais em circulação entre os domínios celulares destacam-se os chamados fatores de transcrição (Carraro et al. 2006, Verdeil et al. 2007).

Fatores de transcrição - o que são e como atuam nos meristemas - Os fatores de transcrição são proteínas codificadas por genes específicos que controlam a expressão de um conjunto de genes-alvo a jusante (do inglês downstream); ou seja, são moléculas sinalizadoras capazes de desencadear e/ou controlar uma ampla gama de cascatas sinalizadoras e, portanto, de respostas celulares. Dessa forma, os fatores de transcrição exercem influência determinante na definição dos destinos celulares em diferentes tecidos vegetais, inclusive nos meristemas e nas regiões vizinhas a eles. Essas proteínas freqüentemente atuam como sinais posicionais nos domínios meristemáticos, estabelecendo as sensibilidades e capacidades de determinados grupos celulares para responder a vias sinalizadoras que regulam o crescimento. Estas funções são freqüentemente exercidas por meio da ligação dos fatores de transcrição às regiões promotoras de genes-alvo a jusante, regulando positiva ou negativamente as suas respectivas transcrições (Scofield \& Murray 2006, David-Schwartz \& Sinha 2007, Bögre et al. 2008).

Muitos fatores de transcrição vêm sendo identificados com o uso de plantas mutantes de Arabidopsis thaliana; entretanto, estudos recentes também vêm proporcionando o conhecimento de algumas destas moléculas sinalizadores em Zea mays, Nicotiana tabacum, Solanum lycopersicum e Oryza sativa (Long et al. 1996, Mayer et al. 1998, Byrne et al. 2000, David-Schwartz \& Sinha 2007). As mutações que interferem na ação dos fatores de transcrição normalmente refletem deficiências funcionais devido à não ativação de determinadas cascatas de transcrição gênica associadas a vias específicas do desenvolvimento. Este tipo de deficiência freqüentemente resulta na conversão de certos tipos de órgãos ou tecidos em formas distintas do esperado, ou ainda na incapacidade de formação de órgãos específicos (Scofield \& Murray 2006).

Um exemplo clássico da importância funcional de um fator de transcrição no desenvolvimento de um ser vivo deu-se pela identificação da mutação no gene ANTENNAPEDIA na mosca Drosophila melanogaster, a qual resultou na substituição das antenas por pernas (Gehring 1987). Este exemplo não demonstra apenas a importância dos fatores de transcrição na especificação dos tipos de órgãos em um organismo, mas também que diferentes vias do desenvolvimento podem ser ativadas pela falha na execução de passos em outra via particular, assim como a ativação de determinadas vias pode desencadear a repressão de outras cascatas de sinalização de uma maneira interdependente (Scofield \& Murray 2006). Nas plantas também se observa este tipo de hierarquia e antagonismo mútuo entre certas vias sinalizadoras que controlam o desenvolvimento, sendo que os fatores de transcrição também participam em grande proporção dos pontos de controle de tais cascatas sinalizadoras nos vegetais (Lohmann \& Weigel 2002, Carraro et al. 2006).

Na realidade, esse tipo de sistema regulatório tem se revelado extremamente complexo nos organismos vegetais; por exemplo, estima-se a existência de 
cerca de 1500 genes que codificam fatores de transcrição nos genomas de A. thaliana e de arroz. Até o presente momento, os fatores de transcrição identificados nas plantas, principalmente em $A$. thaliana, encontram-se classificados como membros de diferentes famílias gênicas devido à presença de características moleculares específicas nas proteínas que eles codificam (Swaminathan et al. 2008). Dentre as famílias de fatores de transcrição encontradas nas plantas estão as denominadas homeodomínio, myb, bHLH, MADS, GRAS, NAC e B3 (Riechmann et al. 2000, Xiong et al. 2005).

Nos vegetais, os fatores de transcrição da família homeodomínio encontram-se agrupados em subfamílias, dentre as quais, de acordo com o estabelecido para $A$. thaliana, estão inseridas as subfamílias KNOX, BELL e HD-ZIP. Apesar dos membros de cada uma destas subfamílias possuírem certas peculiaridades moleculares e, conseqüientemente, modos de ação específicos, todos codificam proteínas com o trecho de ligação ao DNA do tipo homeodomínio, o qual está presente em todos os organismos eucariontes. De maneira curiosa, o gene supracitado ANTENNAPEDIA, encontrado em $D$. melanogaster, pertence à família gênica homeodomínio (Lincoln et al.1994, Long et al. 1996, Himmelbach et al. 2002, Haecker et al. 2004, Scofield \& Murray 2006).

Assim como nos animais, muitos genes da família homeodomínio presentes nas plantas estão envolvidos na regulação do desenvolvimento, sendo que nos vegetais eles encontram-se particularmente associados à regulação dos nichos de células-tronco nos meristemas apicais (Scofield \& Murray 2006). No entanto, conforme será visto adiante, estas redes de transcrição gênica não atuam sozinhas no controle do desenvolvimento vegetal. Na realidade, elas atuam de maneira integrada a outras moléculas sinalizadoras como os hormônios vegetais, moléculas estas imprescindíveis para o controle meristemático e desenvolvimento vegetal como um todo (Tucker \& Laux 2007).

Células meristemáticas - morfologicamente indiferenciadas e funcionalmente diferenciadas - Por um longo tempo a diferenciação celular foi interpretada tomando-se como base apenas as mudanças morfológicas e estruturais de células e tecidos. Dentro dessa perspectiva, as células meristemáticas eram tradicionalmente consideradas indiferenciadas, com base nas suas características do ponto de vista morfológico e estrutural (Sussex 2006). No entanto, abordagens moleculares recentes têm revelado a ocorrência de mudanças celulares anteriores àquelas detectadas nas características fenotípicas (Zhuravlev \& Omelko 2008), o que deu margem a interpretações distintas sobre o grau de diferenciação das células meristemáticas.

Como abordado anteriormente, a regulação da atividade meristemática é dependente, por exemplo, da existência de subgrupos celulares altamente especializados do ponto de vista funcional; cujas funções são determinadas por conjuntos específicos de fatores de transcrição, hormônios, fatores remodeladores da cromatina, dentre outras moléculas sinalizadoras (Guyomarc'h et al. 2007). Por esse motivo, apesar dos meristemas serem formados por células relativamente pouco diferenciadas do ponto de vista morfológico, atualmente, eles também são considerados estruturas altamente diferenciadas sob o ponto de vista funcional (Vernoux \& Benfey 2005). Esta interpretação, portanto, leva em conta o grau de especialização das células meristemáticas, controlado por uma série de modificações nos processos de expressão gênica que podem, por exemplo, ser modulados no nível epigenético (Verdeil et al. 2007, Zhuravlev \& Omelko 2008).

\section{Origem, padrões de organização e funcionamento dos meristemas}

Poucas estruturas são definidas no corpo das angiospermas durante a embriogênese, sendo elas: o hipocótilo (ou epicótilo), a radícula, o(s) cotilédone(s) e os dois meristemas primários - o meristema apical caulinar e o meristema apical radicular. Dentre estes componentes do embrião, apenas os dois meristemas apicais são mantidos durante o desenvolvimento pós-embrionário, e as atividades das suas respectivas populações de células-tronco - conjunto das iniciais estruturais e das iniciais a elas justapostas, oriundas diretamente de suas atividades mitóticas - determinam a arquitetura das partes aérea e subterrânea da planta (Wang \& Li 2008, Chandler et al. 2008).

A origem dos meristemas primários está vinculada à definição do eixo apical-basal embrionário por meio do estabelecimento de dois domínios celulares pluripotentes nas regiões terminais do embrião, os quais coincidem com locais de acúmulo de auxina (Weijers et al. 2005, Friml et al. 2006). Nas fronteiras dos meristemas apicais há domínios celulares específicos que operam um balanço dinâmico entre 
a proliferação e a diferenciação das células recémproduzidas para incorporação em órgãos, sendo cada um deles controlado por um padrão hormonal e um programa específico de expressão gênica. Dessa forma, o destino das células meristemáticas é definido de acordo com a localização celular no meristema, onde a divisão de células-tronco leva ao afastamento das células-filhas rumo à periferia, podendo elas, em seguida, se diferenciar após muitos ciclos mitóticos, ou se juntar a outras células para iniciar um novo órgão (Beveridge et al. 2007, Bögre et al. 2008, Rast \& Simon 2008).

As células localizadas na fronteira entre o meristema e o órgão em formação dependem de sinais emitidos por células localizadas no centro do meristema, desempenhando papel duplo de separação e manutenção de ambos os domínios celulares por elas delimitados. Estas funções são também exercidas por meio da expressão de genes específicos que reduzem a divisão celular local, porém, ativam a expressão gênica no meristema (Bögre et al. 2008, Rast \& Simon 2008).

As regiões periféricas dos meristemas apicais envolvidas na formação de órgãos coincidem com locais de acúmulo de auxina, a qual é transportada de forma controlada e direcionada por proteínas denominadas de PINFORMED (PIN). Estas proteínas encontram-se ligadas à porção apical ou basal da membrana celular e transportam a auxina de maneira polar e específica (Reinhardt et al. 2000, Reinhardt et al. 2003, Benková et al. 2003, Friml et al. 2004). Sendo assim, a auxina é considerada um sinal desencadeador da morfogênese durante o desenvolvimento pós-embrionário das plantas, uma vez que este hormônio, comumente, determina a localização na qual as células adquirirão a identidade de iniciadoras de órgãos (Dubrovsky et al. 2008).

A formação de órgãos envolve diversos passos como a regulação da divisão e expansão celular, diferenciação dos tipos celulares e teciduais, e o estabelecimento do padrão estrutural do órgão como um todo (Irish 2008). Dessa forma, assim como há necessidade de manter as células-tronco dos animais sob controle para prevenir a formação de tumores, as populações de células-tronco vegetais também necessitam de mecanismos regulatórios para prevenir a super-proliferação celular nos meristemas e, consequientemente, prejuízos no desenvolvimento da planta (Dinneny \& Benfey 2008).

Descobertas recentes têm contribuído para o conhecimento dos mecanismos sinalizadores necessários ao controle celular nos meristemas, dentre os quais se destacam programas genéticos e fatores ambientais (Bögre et al.2008). Os hormônios vegetais, como mencionado acima, também desempenham importantes funções nesses processos, especialmente as auxinas na especificação meristemática e iniciação de órgãos (Heisler et al. 2005, de Reuille et al. 2006), e as citocininas no controle da diferenciação celular (Dello-Ioio et al. 2008).

Padrão de organização e funcionamento do meristema apical caulinar - $\mathrm{O}$ meristema apical caulinar (MAC) é a fonte de células para a formação dos tecidos e órgãos que compõem a parte aérea vegetal, sendo que tanto sua organização quanto sua atividade são reguladas por uma sequiência complexa e bem ordenada de expressão gênica. Esse sistema de controle assegura o tamanho e a forma característicos do MAC, bem como equilibra o balanço entre os processos de auto-manutenção das células-tronco com proliferação celular e o fornecimento de novas células para diferenciação e organogênese (Reddy 2008, Wang \& Li 2008). Os principais participantes desta sequiência de expressão gênica, assim como suas inter-relações nas vias de sinalização, foram descritos prioritariamente na planta-modelo A. thaliana.

As primeiras informações sobre a organização do MAC resultaram de estudos histológicos que o revelaram uma estrutura com padrão de distribuição celular ligeiramente bem definido. Muitos pesquisadores buscaram interpretar a maneira pela qual as células estariam organizadas no MAC, sendo que a proposta levantada por Schmidt (1924) baseouse no plano de orientação das divisões celulares. De acordo com esta proposta, o MAC seria subdividido em duas grandes regiões celulares denominadas de "túnica" e "corpo"; a túnica corresponderia ao grupo de células dispostas superficialmente no MAC e que se dividiriam no plano anticlinal (ou longitudinalmente), ao passo que o corpo corresponderia às células localizadas em posição mais interna do MAC e que se dividiriam em todos os planos (Schmidt 1924, Steeves 2006).

A subdivisão simplificada do MAC em túnica e corpo sobrepõe-se a um nível mais complexo de organização, o qual delimita camadas e zonas celulares no MAC de acordo com o tamanho das células, arranjo citoplasmático, assim como freqüência e plano das divisões mitóticas. Dessa forma, o MAC de A. thaliana, por exemplo, possui uma região mais superficial caracterizada pela organização das células em três camadas sobrepostas denominadas de L1, L2 


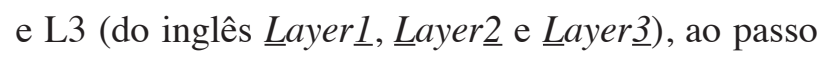
que na região mais interna do meristema destaca-se um grupo pequeno de células formadoras da zona central do MAC. Sabe-se que as camadas L1 e L2 geram a epiderme e a subepiderme dos caules, folhas e flores, e a camada L3 origina os tecidos internos dos órgãos aéreos. Na região de sobreposição entre a camada L3 e a zona central encontra-se o centro organizador (CO) do MAC, cujas células formam, juntamente às suas iniciais imediatas, o nicho de células-tronco que se auto-perpetua por meio de taxas relativamente baixas de divisões mitóticas (Stewart \& Dermen 1970, Steeves 2006, Wang \& Li 2008).

$\mathrm{Na}$ zona periférica do MAC, localizada ao redor deste nicho organizador, encontram-se as células derivadas, morfologicamente indiferenciadas, que se dividem mais rapidamente. A diferenciação delas, por sua vez, ocorre em regiões específicas dos flancos do MAC para a formação de primórdios foliares, sendo que o acúmulo localizado de auxina nestas regiões representa um componente-chave na definição dos padrões de filotaxia e de iniciação de novos órgãos caulinares em geral. Além disso, a especificação do destino celular no MAC se dá por um processo dinâmico intimamente relacionado a alterações nos padrões de crescimento e mudanças transitórias na ativação/repressão gênica (Furutani et al. 2004, Jonsson et al. 2006, Wang \& Li 2008, Reddy 2008).

A manutenção do nicho de células-tronco nas imediações do CO é dependente da expressão do gene que transcreve o fator de transcrição homeodomínio WUSCHEL (WUS), o qual age especificamente neste local como sinal primário para a organização das células-tronco, conferindo identidade meristemática caulinar e inibindo a diferenciação. A importância desse gene para o estabelecimento e a manutenção do MAC foi claramente evidenciada nos mutantes wus de $A$. thaliana, os quais apresentam parada prematura da atividade do MAC devido à diferenciação de todas as células-tronco, e a conseqüente falha na formação de tecidos e órgãos caulinares envolvidos no desenvolvimento das plântulas (Leibfried et al. 2005, Mayer et al. 1998, Bögre et al. 2008).

WUS exerce sua função na manutenção da funcionalidade do nicho de células-tronco no MAC por meio da interação com as proteínas codificadas pelos genes CLAVATA1 (CLV1), CLAVATA2 (CLV2) e CLAVATA3 (CLV3), a qual se dá pelo trânsito intercelular de WUS e CLV3 via plasmodesmas. Esta interação parece formar um sistema dinâmico de regulação espacial e temporal das divisões celulares no CO por feedback, uma vez que mutantes de genes da classe CLV apresentam MACs maiores, com o domínio das células-tronco aumentado, coincidindo com a expansão da região de expressão de WUS e com o CO altamente desorganizado (Schoof et al. 2000, Baurle \& Laux 2003, Williams \& Fletcher 2005).

De acordo com estas informações, o modelo vigente para explicar o mecanismo que assegura a manutenção da organização e atividade do MAC de A. thaliana propõe que WUS seja expresso no $\mathrm{CO}$, logo abaixo das células que expressam e liberam CLV3, um peptídeo sinalizador que aparentemente atua como ligante e ativador do complexo cinase no receptor formado pela junção de CLV1 e CLV2. Uma vez ativado, o sistema CLV1/CLV2/CLV3 restringe o domínio de expressão de WUS a poucas células no CO, e como WUS também ativa a expressão de $C L V 3$ na região vizinha ao $\mathrm{CO}$, ele acaba, portanto, limitando sua própria expressão e promovendo a expansão do domínio das célulastronco (figura 1). Dessa forma, a interação entre WUS e CLAVATAs parece estabelecer um mecanismo de auto-regulação que garante a manutenção de um número aproximadamente constante de células-tronco no MAC. Entretanto, evidências recentes levantam a possibilidade da existência, ainda que não totalmente elucidada, de mecanismos alternativos de interação entre WUS e CLV3 para o controle das células-tronco no MAC (Brand et al. 2000, Schoof et al. 2000, Green et al. 2005, Reddy 2008).

Além do sistema WUS/CLAVATAs, o estabelecimento e a manutenção do MAC também dependem da expressão de genes KNOX, como é o caso de SHOOTMERISTEMLESS (STM). Este gene codifica um fator de transcrição encontrado em toda a extensão do MAC onde não há diferenciação celular (figura 1), e sua expressão parece ser essencial para o correto funcionamento meristemático, uma vez que plantas mutantes com distúrbios deste fator de transcrição falham na manutenção da organização e atividade do MAC (Clark et al. 1996, Endrizzi et al. 1996, Long et al. 1996).

Os fenótipos dos mutantes stm e wus são ligeiramente semelhantes entre si, marcados pela perda precoce do potencial meristemático das células do MAC, levando o meristema ao esgotamento da atividade e à perda do crescimento aberto (Endrizzi et al. 1996, Laux et al. 1996). No entanto, tais mutantes diferem no modo com que estes eventos ocorrem, uma vez que em stm as células meristemáticas são direcionadas precocemente à formação de órgãos, e em wus elas são mantidas em um estado desorganizado e 
não-meristemático em termos histológicos (Endrizzi et al. 1996, Mayer et al. 1998).

STM atua como repressor da diferenciação celular no MAC, mantendo as células meristemáticas em um estado morfologicamente indiferenciado, bem como permitindo a proliferação celular mais rápida nos flancos do meristema onde não há formação de primórdios foliares (Long et al. 1996, Lenhard et al . 2002, Scofield \& Murray 2006, Bögre et al. 2008). Parte destas funções de STM deve-se à sua atividade na regulação direta dos teores de citocininas por meio da ativação da expressão do gene isopentenil transferase (IPT7, no caso de A. thaliana), que codifica uma enzima determinante na via biossintética de citocininas. Este mecanismo auxilia na manutenção de teores relativamente elevados de citocininas no MAC, o que é tido como necessário para a preservação da atividade e identidade das células-tronco no centro do meristema caulinar (Jasinski et al. 2005, Scofield \& Murray 2006, Kyozuka 2007).

$\mathrm{Na}$ realidade, como ilustrado na figura 1, a regulação dos teores e da sinalização de citocininas possui estreita relação com dois componentes-chave do sistema de controle gênico no MAC: STM, participando tanto por meio do mecanismo supracitado quanto pelo papel promotor das citocininas sobre sua própria expressão (Jasinski et al. 2005), e WUS, inibindo diretamente a expressão de alguns reguladores negativos de respostas às citocininas (ARR5, ARR6, ARR7 e ARR15 de A.thaliana), e tendo a sua própria expressão promovida por esta classe hormonal (Leibfried et al. 2005).

A conexão entre as vias de sinalização das citocininas e auxinas pode ocorrer, por exemplo, por meio do gene MONOPTEROS, que codifica o fator de transcrição pertencente à família de reguladores de respostas às auxinas (também conhecidos como $A R F s$ ), desempenhando papel importante na organização estrutural do MAC durante e após a embriogênese (Hardtke \& Berleth 1998, Guilfoyle et al. 1998, Vidaurre et al. 2007). O balanço entre estas duas classes hormonais possui ação crítica na definição dos destinos celulares nos flancos do MAC: a razão auxina/citocinina elevada, combinada com teores aumentados de giberelinas e a expressão do gene ASYMMETRIC LEAVES1 (AS1), determinam o local de iniciação do primórdio foliar (Jasinski et al. 2005, Shani et al. 2006, Kepinski 2006).

Como ilustrado na figura 1 , sabe-se que a atuação do fator de transcrição AS1 nas regiões de organogênese foliar ocorre em conjunto com AS2
(ASYMMETRIC LEAVES2) por meio da inibição direta da expressão dos genes $K N O X$, incluindo $S T M$, a qual é realizada pela ligação do complexo protéico $\mathrm{AS} 1 \mathrm{AS} 2$ à região promotora dos genes $K N O X$, silenciando as suas respectivas expressões (Guo et al. 2008). Em contrapartida, no interior do MAC os fatores de transcrição KNOX parecem atuar, pelo menos em parte, na inibição da expressão de $A S 1$ (Byrne et al. 2000), assim como inibem o aumento dos teores de giberelinas tanto pela repressão do gene GA20-oxidase, o qual codifica uma enzima-chave na via biossintética desta classe hormonal, assim como pela indução da expressão de GA2-oxidase, gene que codifica uma enzima regulatória do passo que leva à inativação de giberelinas (Sakamoto et al. 2001a, b, Jasinski et al. 2005). Além disso, foi verificado que as citocininas e as giberelinas também desempenham suas atividades antagônicas no MAC por meio da inibição recíproca de vias que modulam tanto a biossíntese quanto a ação desses hormônios (Shani et al. 2006).

Por outro lado, como ilustrado na figura 1, as giberelinas e auxinas sobrepõem-se no que diz respeito à sua distribuição e ação nos flancos do MAC, ao passo que ambas encontram-se presentes em concentrações relativamente elevadas em regiões específicas da periferia meristemática, onde participam no crescimento por expansão celular (Veit 2009). Como citado anteriormente, o acúmulo localizado de auxina nos flancos do MAC, controlado por proteínas transportadoras deste hormônio (PIN1 e AUX/LAX), marcam a posição onde ocorrerá a formação do primórdio foliar, coincidindo com teores de citocininas relativamente reduzidos (Rast \& Simon 2008).

Como representado na figura 1 , a regulação do processo que marca as células nos flancos do MAC para a organogênese envolve outros componentes além dos já citados, como é o caso dos genes $C U P$ SHAPED COTYLEDON 1 e 2 (CUC1/CUC2), os quais inibem localmente a proliferação celular e contribuem para o estabelecimento das fronteiras meristemáticas para organogênese (Vroemen et al. 2003, Aida \& Tasaka 2006, Heisler \& Jönsson 2007, Gómez-Mena \& Sablowski 2008).

Padrão de organização e funcionamento do meristema apical radicular - Conforme já mencionado, os papéis promotores das auxinas e citocininas sobre a proliferação versus diferenciação celular nos meristemas caulinares e radiculares apicais são fortemente opostos. Diferentemente do 
Região de alongamento e diferenciação celular ( $\uparrow[\mathrm{GA}]$ e $\downarrow$ [Cks] )

Região de iniciação do primórdio foliar $(\uparrow[\mathrm{GA}], \uparrow[\mathrm{AIA}]$ e $\downarrow[\mathrm{Cks}])$

Região de elevada taxa mitótica $(\uparrow[\mathrm{Cks}] \mathrm{e} \downarrow[\mathrm{GA}])$

Centro organizador

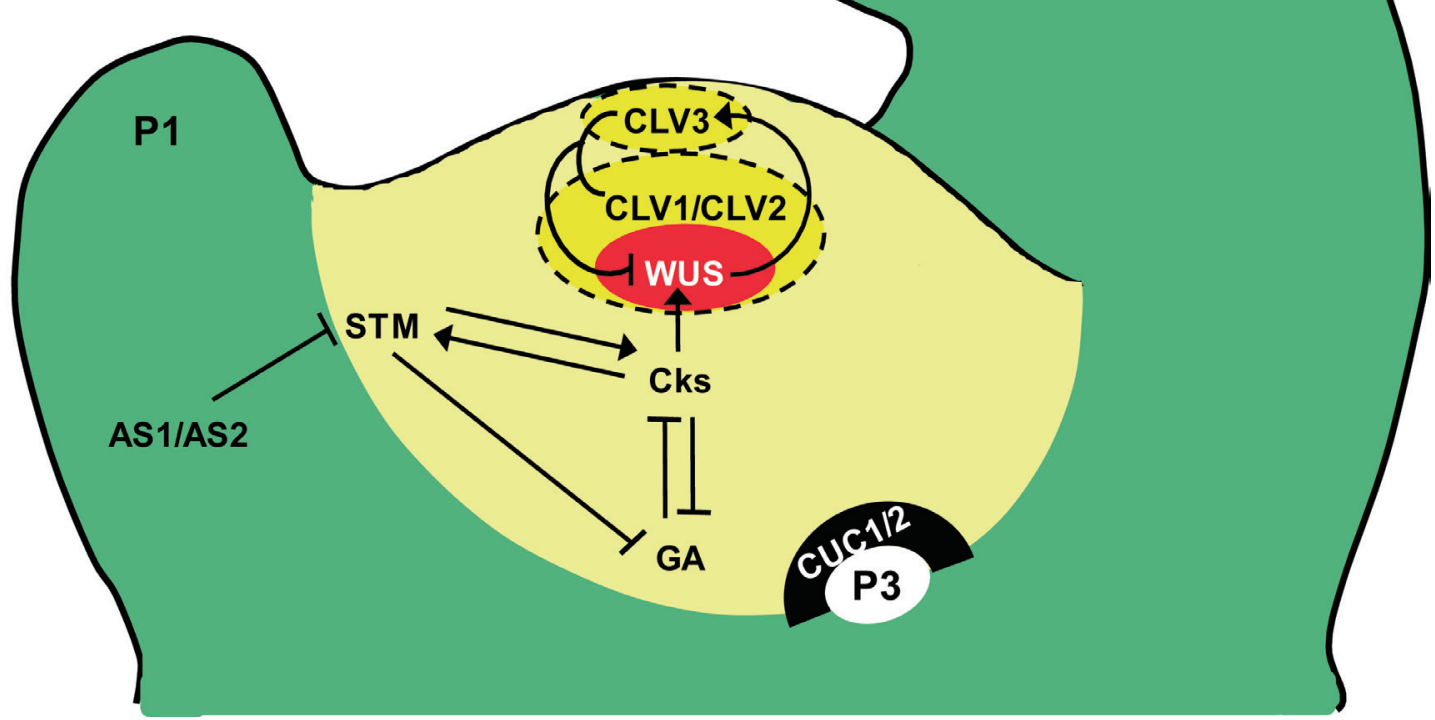

Figura 1. Diagrama simplificado de um ápice radicular, mostrando os padrões de localização e interação dos principais elementos que asseguram a organização e a manutenção da atividade do meristema apical caulinar (MAC). Flechas indicam regulação positiva e barras em T indicam regulação negativa. P1, P2 e P3 indicam os primórdios foliares em ordem temporal de formação. O fator de transcrição WUS (WUSCHEL) atua em conjunto com as proteínas CLAVATA 1, 2 e 3 (CLVs 1, 2 e 3) no controle do nicho de células-tronco. SHOOTMERISTEMLESS (STM), por sua vez, atua juntamente às citocininas (CKs) e giberelinas (GA) na região de elevada taxa mitótica do MAC, estabelecendo um balanço entre estas classes hormonais favorável às CKs. Na região de iniciação dos primórdios foliares verifica-se a predominância de GA e AIA (ácido indolilacético, a principal auxina de ocorrência natural), assim como é separada do MAC pela expressão dos genes CUP-SHAPED COTYLEDON 1 e 2 (CUC1/CUC2). ASYMMETRIC LEAVES1 e 2 (AS1/AS2) atuam em conjunto na região periférica do MAC onde ocorre alongamento e/ou diferenciação celular.

Figure 1. Simplified schematic representation of a shoot tip showing the general patterns of interactions between some of the main signalling molecules responsible for the shoot apical meristem (SAM) architecture and activity maintenance. The proposed model was mainly based on the model plant Arabidopsis thaliana. Arrows and "T"-bars represent positive and negative regulation, respectively. P1, P2 and P3 indicate leaf primordia in temporal order of formation. The transcription factor WUS (WUSCHEL), expressed in the organizing center (red circle), acts together with the proteins CLAVATA 1, 2 and 3 (CLV1, CLV2 and CLV3) to control the stem cell niche. SHOOT MERISTEMLESS (STM) operates with cytokinins (Cks) and gibberellins (GA) in the region of the SAM with more frequent cellular division (yellow region), establishing a hormonal balance between these hormonal classes favorable to CKs. In the region of leaf primordia initiation, marked in white, a predominance of GA and IAA (indolilacetic acid, the main natural auxin species) is evident; the separation of this SAM region (boundary marked in black) depends on the expression of CUP-SHAPED COTYLEDON 1 and 2 (CUC1/2) genes. ASYMMETRIC LEAVES 1 and 2 (AS1/AS2) act together in the SAM peripheral region, marked in green, where cell elongation and/or division occurs. 


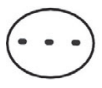

Região do estelo

(expressão de SHR)

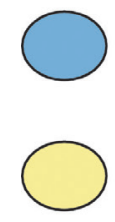

Região de elevada divisão celular (个 $[\mathrm{AIA}]$ )

Região de maior expressão de PLT1/PLT2 $(\uparrow[A \mid A])$

Centro quiescente $(\uparrow[A I A])$

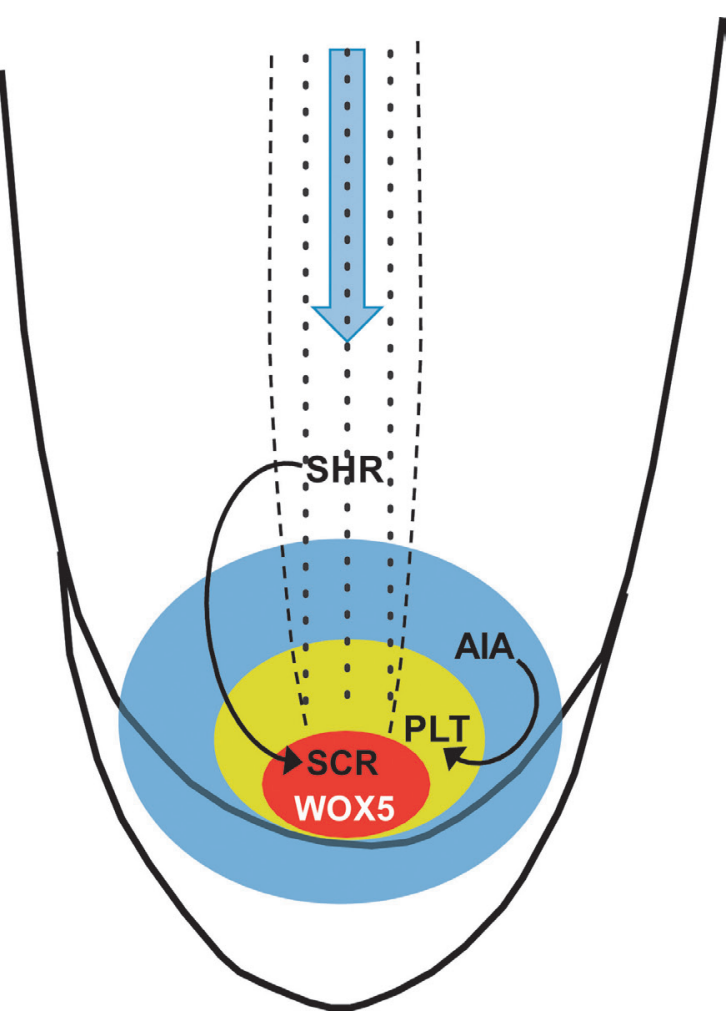

Figura 2. Diagrama simplificado de um ápice radicular, mostrando os padrões de localização e interação dos principais elementos que asseguram a organização e a manutenção da atividade do meristema apical radicular (MAR). Flechas pretas indicam regulação positiva e a seta azul indica a direção preferencial do fluxo de auxina rumo ao MAR, o qual auxilia no acúmulo desta classe hormonal (círculo azul) na região que engloba o nicho de células-tronco. Nesta região a auxina participa no controle da expressão dos genes PLT1 e PLT2 (PLETHORA1 e 2) (círculo amarelo), os quais desempenham papel determinante na manutenção do nicho de células-tronco. Esta função é compartilhada com os fatores de transcrição WOX5 (WUSCHEL-related homeobox5) e SCR (SCARECROW), sendo a expressão do último regulada por SHR (SHORTROOT) proveniente do estelo.

Figure 2. Schematic representation of the root tip showing the general localization and the essential signaling molecule interactions involved in the root apical meristem (RAM) architecture and activity maintenance. Black arrows indicate positive regulation and the blue arrow indicates the preferential direction of the auxin flow towards the RAM, which contributes to the accumulation of this hormone (blue circle) in the apical region that includes the stem cell niche. In this region, auxin participates in the control of PLT genes expression (region with higher expression of PLT1 and PLT2 delimited by a yellow circle), which play a crucial role in the maintenance of the stem cell niche. This function is shared by the transcription factors WOX5 (WUSCHEL-related homeobox5) and SCR (SCARECROW), being the expression of SCR regulated by SHR (SHORT ROOT) derived from the estele.

observado no MAC, os efeitos antagônicos entre estas duas classes hormonais determinam o tamanho do meristema apical radicular (MAR) por meio do papel promotor da auxina sobre as divisões celulares, bem como pelo papel promotor desempenhado pelas citocininas na diferenciação celular (Grieneisen et al. 2007, Dello-Ioio et al. 2007). No entanto, ambos os meristemas apicais possuem em comum um sistema sinalizador coordenado por fatores de transcrição importantes no controle e manutenção de suas célulastronco (Sarkar et al. 2007).

A distribuição da auxina na raiz, coordenada principalmente por proteínas PIN, é um componente- chave para o estabelecimento e manutenção do MAR, controlando rigidamente as divisões celulares, especialmente, devido ao seu acúmulo na região que engloba as células-tronco radiculares (figura $2)$. As células-tronco do MAR geram células derivadas que irão sofrer um número determinado de divisões mitóticas antes de entrarem na zona de alongamento celular, para, finalmente, diferenciaremse e alcançarem a maturidade. A taxa de crescimento radicular e o tamanho do MAR são definidos, portanto, pela taxa de divisão celular no meristema e pela extensão de diferenciação celular que ocorre na zona de transição entre a região de divisão e de alongamento 
celular (Magyar et al. 2005, Grieneisen et al. 2007, Bögre et al. 2008).

Assim como o MAC possui o centro organizador constituído por células-tronco com baixa taxa de divisão celular e que conferem a identidade caulinar, o MAR possui uma região equivalente denominada centro quiescente (CQ), donde se presume que sejam originadas todas as células da raiz (Ivanov 2004). O CQ de A.thaliana é composto por apenas quatro células que raramente entram em divisão celular, sendo que estas, juntamente com as células iniciais justapostas ao CQ, formam o nicho de células-tronco do MAR (Weigel \& Jürgens 2002, Laux 2003, Scheres 2007).

O CQ mantém a identidade de células-tronco das suas iniciais imediatas por meio da sinalização de curta distância estabelecida pelo contato direto célula-a-célula, via plasmodesmas, o qual assegura a manutenção do posicionamento apical e do número de células-tronco nas raízes em crescimento. A perda das conexões íntimas entre as células derivadas da divisão de iniciais adjacentes ao CQ leva à posterior diferenciação celular. Assim, o CQ pode ser interpretado como um grupo celular com organização dinâmica e específica do MAR, e não como uma população de células-tronco formadas durante a embriogênese e assim mantidas durante a vida da planta (van den Berg et al. 1997, Ivanov 2004, Dinneny \& Benfey 2008).

Além da influência do acúmulo de auxina, o nicho das células-tronco no MAR depende também da ação combinada de diferentes genes, como PLETHORAI (PLT1), PLETHORA2 (PLT2), SCARECROW (SCR), e SHORT ROOT (SHR) (Di Laurenzio et al. 1996, Helariutta et al. 2000, Sabatini et al. 2003, Aida et al. 2004). Os fatores de transcrição PLT1 e PLT2 atuam de maneira aditiva e positiva na manutenção da organização e funcionamento do MAR, tanto que os mutantes plt1plt2 (com deficiência para ambos os genes PLTS) apresentam severa inibição do crescimento radicular devido à diferenciação prematura das células do MAR. Conforme esquematizado na figura 2, a região de acúmulo de auxina coincide com o local onde as proteínas PLTs também se encontram em maior concentração, região correspondente ao nicho das células-tronco radicular, onde promovem o estabelecimento e manutenção deste grupo de células. No entanto, concentrações relativamente mais reduzidas de PLTs estão relacionadas ao estímulo da proliferação celular no MAR. Os genes-alvo que se encontram sob regulação dos fatores de transcrição PLTs ainda são pouco conhecidos, porém, sabe-se que a transcrição de PLTs é promovida por teores elevados de auxina e é inibida pelo produto de transcrição do gene RETINBLASTOMA RELATED1, um homólogo em plantas do gene supressor de tumores humanos (Aida et al. 2004, Galinha et al. 2007, Bögre et al. 2008).

A organização e a manutenção do MAR são controladas também por um mecanismo paralelo, porém complementar, ao sistema coordenado por PLTs, no qual participam os fatores de transcrição SHR e SCR; ambos pertencentes à família GRAS. $S C R$ é expresso nas células do CQ e da endoderme, sendo que as raízes de mutantes scr apresentam período de crescimento limitado, coincidindo com a redução precoce do número de células no MAR, ausência de CQ e a não-separação entre a endoderme e a camada mais interna do córtex. $S H R$, por sua vez, é transcrito no estelo (periciclo e sistema vascular); plantas mutantes para este fator de transcrição apresentam deficiências fenotípicas semelhantes àquelas observadas nos mutantes scr (Benfey et al. 1993, Scheres et al. 1995, Ivanov 2004).

Atualmente, sabe-se que tanto SCR quanto SHR desempenham funções relacionadas à especificação e regulação funcional do nicho de células-tronco do MAR, assim como controlam as divisões assimétricas de células derivadas da inicial do córtex e endoderme, definindo também o destino das células endodérmicas (Di Laurenzio et al. 1996, Helariutta et al. 2000, Heidstra et al. 2004, Sena et al. 2004). O mecanismo de ação desses fatores de transcrição ocorre por meio do trânsito da proteína codificada pelo gene $S H R$, via plasmodesmas, do estelo para células do CQ, iniciais do córtex/endoderme e células da própria endoderme, onde interage com a proteína SCR para formar o complexo protéico SHR/SCR, localizado nos núcleos, o qual leva à ativação da transcrição gênica do próprio $S C R$ nestes locais (figura 2). Adicionalmente, SHR atua na modulação direta tanto da biossíntese de brassinoesteróides quanto na sinalização das giberelinas, participando também, de maneira indireta, da regulação dos teores / sinalização de auxina, brassinoesteróides e giberelinas (Nakajima et al.2001, Shimada et al.2003, Levesque et al. 2006, Cui et al. 2007, Benková \& Hejátko 2009).

Assim como para o MAC, espera-se que outras vias sinalizadoras paralelas ou que se cruzem à PLT1/ PLT2 e à SHR/SCR sejam descobertas no controle da organização e atividade do MAR. Dentre as moléculas sinalizadoras que vêm sendo identificadas como importantes para assegurar as funções do MAR, encontra-se o gene WOX5 (do Inglês WUSCHEL- 
related homeobox5), o qual é expresso especificamente no CQ e cuja perda de função nas células iniciais do MAR causa a diferenciação terminal das células deste meristema (figura 2). WOX5 representa um gene homólogo ao WUS encontrado no CO do MAC, e sua expressão depende da sinalização dada pelas auxinas via MONOPTEROS, fornecendo indicações de que a auxina atuaria na regulação de genes da família WOX pelo menos nas raízes. No entanto, até o presente momento não foram encontrados indícios de uma relação equivalente envolvendo a regulação de $W U S$ por auxina no MAC (Kamiya et al. 2003, Sarkar et al. 2007, Veit 2009).

A expressão especificamente localizada de WOX5 no CQ do MAR, assim como de WUS no CO do MAC, parece atuar na manutenção do nicho de células-tronco, inibindo a diferenciação destas células, sem, todavia, participar da determinação do destino de células filhas das iniciais meristemáticas (Tucker \& Laux 2007). Apesar da descoberta de WOX5 ter acenado com a possibilidade da existência de um mecanismo regulador do nicho de células-tronco do MAR equivalente ao sistema WUS/CLVs presente no MAC, as evidências obtidas até o momento não sustentam tal hipótese. Uma das contradições desta proposta decorre do fato das proteínas relacionadas à CLV encontradas nas raízes (proteínas CLE), apesar de serem expressas no MAR e atuarem na redução do número de células meristemáticas, tal qual CLV3 no MAC, não terem sua ação relacionada ao controle das células do CQ, opondo-se à ação de CLV3 no MAC, o qual contribui na regulação do número de células no CO por inibir a expressão de WUS (CasamitjanaMartinez et al. 2003, Ivanov 2004).

Assim, apesar do avanço considerável obtido no entendimento de alguns mecanismos regulatórios das células do MAR, estes ainda são menos compreendidos do que os envolvidos no controle do MAC. Por exemplo, a despeito da importância do balanço redox na regulação da quiescência das células no MAR, via ação de auxina (Kerk \& Feldman 1995, Jiang et al. 2003, Ivanov 2004), não se sabe ainda exatamente como esse mecanismo interage com os demais sinais envolvidos na manutenção e atividade do MAR.

\footnotetext{
Padrões de organização e funcionamento do periciclo e meristemas axilares - Além dos meristemas apicais (primários) que são especificados durante a embriogênese (MAC e MAR), muitos tipos meristemáticos são formados durante o desenvolvimento pós-embrionário, destacando-se os
}

meristemas presentes nos sistemas caulinar e radicular, responsáveis pela formação, respectivamente, de gemas axilares e raízes laterais (Beveridge et al.2007).

Ainda não está totalmente elucidado se as células responsáveis pela origem pós-embrionária desses meristemas são definidas em decorrência da atividade do MAC e/ou do MAR, ou se elas são especificadas de novo durante a diferenciação celular. No entanto, a hipótese mais aceita para a sua origem na maioria das plantas defende que os meristemas axilares caulinares derivariam de grupos de células separadas do MAC durante a iniciação do primórdio foliar que manteriam a identidade meristemática nas axilas foliares, enquanto as raízes laterais seriam iniciadas a partir do periciclo, cujas células reteriam a potencialidade meristemática após deixarem o MAR (DiDonato et al. 2004, Maughan et al. 2006, Beveridge et al.2007).

Na parte aérea pode-se encontrar um ou mais meristema(s) axilar(es) na base de cada folha originada. Em caules no estado vegetativo, a retomada da atividade dos meristemas axilares ocorre em ordem acrópeta, primeiro nas axilas das folhas mais maduras e distantes do ápice caulinar e, posteriormente, nas axilas de folhas mais jovens (Long \& Barton 2000). Os meristemas axilares possuem o mesmo potencial de desenvolvimento do MAC, uma vez que cada um deles pode formar uma ramificação caulinar completa ou inflorescências durante o desenvolvimento reprodutivo. Sendo assim, os meristemas axilares são os principais elementos na determinação da arquitetura e do sucesso reprodutivo das plantas. No entanto, o padrão de ramificação caulinar no estado vegetativo não depende apenas da formação dos meristemas axilares, mas também do controle negativo exercido pelo ápice do caule principal sobre a liberação das gemas laterais (Schmitz \& Theres 2005, Ongaro \& Leyser 2008, Ongaro et al. 2008).

Esta flexibilidade na atividade dos meristemas axilares possibilita uma variação considerável na arquitetura do sistema caulinar, permitindo que a planta adapte sua forma às condições ambientais vigentes. De fato, o desenvolvimento das gemas formadas pelos meristemas axilares é regulado por vários sinais ambientais e endógenos. No entanto, os mecanismos sinalizadores mais finos envolvidos no controle deste processo são ainda pouco compreendidos. Dentre as moléculas conhecidas como importantes mediadoras na transdução dos sinais ambientais que regulam a atividade desses meristemas destacam-se as classes hormonais das citocininas e auxinas (Cline 1991, Simons et al. 2007, Ongaro \& Leyser 2008, Ongaro et al. 2008). 
O estágio inicial do desenvolvimento dos meristemas axilares coincide com alguns pontos de controle da iniciação dos primórdios foliares nos flancos do MAC, cujos elementos sinalizadores foram apresentados no item anterior. Este processo também é caracterizado pela ausência inicial da expressão de $C L V 3$ e WUS, os quais são tidos como mantenedores da população de células-tronco no MAC, ao passo que a expressão destes genes é re-estabelecida no MAC do ramo lateral logo após a liberação das gemas axilares para o crescimento (McSteen \& Leyser 2005, Keller et al. 2006, Beveridge et al. 2007).

Ao contrário do que é observado no caule, a formação de órgãos laterais na raiz ocorre a certa distância do MAR, a partir do periciclo, tecido este que difere amplamente dos tecidos vegetais maduros por manter a ploidia característica da espécie, assim como ocorre nos meristemas apicais do caule e da raiz (D’Amato 1978). Nas plantas com raízes gemíferas, as gemas formadas endogenamente são também originadas a partir do periciclo. Nestas plantas, as células do periciclo formam primórdios de raízes laterais quando na presença de concentrações favoráveis de auxina, enquanto que teores relativamente mais elevados de citocininas desencadeiam a diferenciação de primórdios de gemas; no entanto, em termos histológicos ambos os primórdios de órgãos são semelhantes nos estágios iniciais de formação (Peterson 1975).

Recentemente verificou-se que o periciclo parece ser um meristema constituído por duas populações de células com potenciais diferenciados de desenvolvimento; o periciclo xilemático parece apresentar maior pluripotencialidade do que se supunha até pouco tempo atrás, ao passo que o periciclo floemático parece não apresentar equivalência em tal atributo de desenvolvimento (Atta et al.2009). Dessa forma, algumas células do periciclo, localizadas na posição oposta aos pólos xilemáticos, retêm a atividade meristemática após deixar o MAR, mantendo a potencialidade organogenética inerente a esse órgão (Maughan et al.2006, Beveridge et al. 2007). Além disso, as células do periciclo envolvidas na iniciação de raízes laterais possuem características citológicas tipicamente meristemáticas, como citoplasma denso, núcleos grandes e vacúolos pequenos (Dubrovsky et al.2001, Parizot et al.2007). Uma vez definido o grupo de células que irá se dividir e formar o primórdio de raiz lateral, este se diferencia em um órgão com um estelo central e um meristema apical ativo, permitindo que a raiz lateral cresça de maneira semelhante à raiz primária (Mathesius 2008).
De maneira intrigante, indícios consistentes deram indicações de que um maior número de células do periciclo possuiria potencial para iniciar a formação de raízes laterais do que as poucas que, de fato, se envolvem no processo. De acordo com essa sugestão, todas as células do periciclo apresentariam capacidade de entrar rapidamente em divisão mitótica devido à expressão contínua de genes que codificam algumas proteínas determinantes para a progressão do ciclo celular. No entanto, até pouco tempo atrás inexistiam descrições de marcadores específicos que possibilitassem a identificação precisa das células que seriam recrutadas como iniciadoras de raízes laterais no periciclo, ou ainda de mutantes deficientes especificamente na definição destas células (Roudier $e t$ al.2003, De Smet et al.2006, Beveridge et al.2007).

Sobre esta questão, Dubrovsky et al. (2008) demonstraram recentemente que o acúmulo localizado de auxina nas células do periciclo representa um sinal necessário e suficiente para especificar a identidade das células iniciadoras de raízes laterais. De acordo com estes autores, a ativação de respostas à auxina em uma região específica do periciclo (visualizada em plantas transformadas com o promotor DR5, sensível à auxina) estaria relacionada a um padrão de divisões celulares que desencadearia a formação do primórdio de raiz lateral. Estes resultados vieram esclarecer a maneira geral pela qual a auxina participa na formação de raízes laterais, uma vez que muitos indícios anteriores já a indicavam como um regulador central neste processo de organogênese (Fukaki et al. 2007).

Além dos meristemas apresentados até o momento (axilares do caule e periciclo na raiz), outros tipos meristemáticos podem ser formados durante o desenvolvimento pós-embrionário vegetal. Um exemplo interessante dá-se pela formação de estruturas nodulares em raízes de leguminosas resultantes da interação simbiótica entre estas plantas e algumas bactérias fixadoras de nitrogênio do gênero Rhizobium. Os nódulos normalmente são iniciados de novo por meio de divisões celulares no córtex radicular, resultantes da sinalização desencadeada pela infecção bacteriana na epiderme da raiz, levando à consolidação do primórdio nodular com um meristema funcional que lhe permitirá crescer (Hirsch 1992, Mathesius 2008, Oldroyd \& Downie 2008).

Até o momento foram identificados poucos genes que codificam reguladores do desenvolvimento nodular em raízes de leguminosas, no entanto, um dos elementos reconhecidos como cruciais na formação destas estruturas são os chamados fatores de nodulação 
(fatores Nod). Os fatores Nod participam na ativação concomitante de respostas na epiderme radicular (decorrentes da infecção bacteriana) e no córtex da raiz (que levam à formação do meristema nodular). $\mathrm{O}$ estabelecimento do meristema nodular é mediado por mudanças hormonais, sendo as citocininas de importância central na maioria dos casos (Oldroyd \& Downie 2008, Mathesius 2008, Vernié et al. 2008).

Estado determinado e indeterminado dos meristemas - Os meristemas podem perder a capacidade de formação de novas células, seja pela parada do seu funcionamento em um período específico do desenvolvimento vegetal, seja pela diferenciação de suas células-tronco em estruturas especializadas. Em função disso, os meristemas são chamados de determinados ou indeterminados conforme, respectivamente, a manutenção ou a perda da organização e atividade meristemáticas típicas de órgãos em crescimento (Bathélémy \& Caraglio 2007, Shishkova et al. 2008).

No meristema determinado há um programa genético que desencadeia a parada da produção de novas células em um estágio específico do desenvolvimento vegetal. Este tipo de meristema é comumente responsável pela formação de órgãos com tamanho e forma definidos; enquanto os meristemas indeterminados estão mais relacionados à formação de partes vegetais que podem crescer por períodos variáveis e que apresentam diferentes tamanhos e formatos, de acordo com as condições ambientais (Sablowski 2007).

Os nódulos fixadores de nitrogênio presentes nas raízes de plantas leguminosas são bons exemplos de alteração na determinação meristemática durante o desenvolvimento, uma vez que, normalmente, são indeterminados no início do desenvolvimento por possuírem um meristema ativo; por outro lado, quando maduros usualmente perdem a atividade meristemática, sendo, portanto, determinados e desprovidos da capacidade de crescimento. Por outro lado, os meristemas foliares e a maioria dos florais podem ser lembrados como exemplos de meristemas com padrão de atividade determinado na parte aérea vegetal (Bauer et al. 1997, Shishkova et al. 2008).

Os mecanismos de controle hormonal e gênico dos meristemas apicais relatados nos itens anteriores ilustram alguns dos pontos que asseguram a organização e a atividade meristemáticas e, portanto, a manutenção do caráter indeterminado dos mesmos. Assim, em um MAC indeterminado ativo o estado vegetativo pode ser mantido por um longo período, durante o qual primórdios foliares são formados sucessivamente em seus flancos, originando também os meristemas axilares. Dependendo de fatores extrínsecos e/ou intrínsecos, o MAC pode manter-se no estado vegetativo, gerando um número indeterminado de fitômeros, ou ainda entrar em um programa de desenvolvimento determinado, produzindo um número fixo de segmentos caulinares, o que normalmente resulta na formação de estruturas reprodutivas (McSteen \& Leyser 2005, Barthélémy \& Caraglio 2007, Shishkova et al. 2008).

A conversão do MAC vegetativo em meristema floral (mudança de fase) é induzida por múltiplos sinais ambientais e endógenos que, em última instância, convergem em pontos-chave de regulação para o estabelecimento da identidade floral. Uma vez sob controle desta rede sinalizadora, o meristema apical normalmente adquire uma natureza determinada refletida pela diferenciação terminal de suas células, as quais se tornam comprometidas com a formação de um número específico de órgãos florais (Zik \& Irish 2003, Sablowski 2007, Shishkova et al. 2008).

Alguns dos sinais endógenos indutores da mudança de fase do MAC são produzidos nas folhas e transportados para o meristema apical caulinar, desencadeando uma série de mudanças, inclusive morfológicas, denominadas coletivamente de evocação floral. Em geral, os meristemas florais apresentam crescimento determinado, sendo que em algumas espécies o MAC pode se transformar em um meristema floral que originará uma única flor, ao passo que em outras, como $A$. thaliana, o MAC vegetativo é inicialmente convertido em uma inflorescência, a qual, posteriormente, produz meristemas florais em seus flancos. Em algumas poucas espécies o MAC vegetativo pode originar um meristema floral de natureza indeterminada, o qual não apresenta um programa genético que pré-defina o número de órgãos florais que serão formados (Zik \& Irish 2003, Sablowski 2007, Kanrar et al. 2008).

O estabelecimento do padrão determinado de crescimento do meristema floral depende da expressão de genes regulatórios que conferem a identidade floral. Estes genes fazem parte de um programa de expressão gênica iniciada durante a transição do meristema vegetativo para o desenvolvimento reprodutivo (Zik \& Irish 2003, Sablowski et al. 2007, Kanrar et al. 2008). Assim, a indução floral está atrelada ao estabelecimento do crescimento determinado do meristema apical, sendo que este processo coincide 




Figura 3. Padrões de expressão e interação de alguns genes importantes para o estabelecimento do estado determinado do meristema caulinar floral. Flechas indicam regulação positiva e barras em $\mathrm{T}$ indicam regulação negativa. Linha tracejada contínua indica interação demonstrada experimentalmente entre os elementos; e linha tracejada indica interação possível entre os elementos, porém, trata-se de uma via sinalizadora em processo de elucidação. LFY (LEAFY - elemento fundamental para a identidade caulinar floral) e WUS (WUSCHEL - determinante para a identidade caulinar vegetativa) atuam conjuntamente na indução da expressão de $A G$ ( $A G A M O U S$ ), cujo produto de transcrição é tido com repressor da expressão de WUS, levando à extinção do nicho das células-tronco e, consequentemente, o estabelecimento do crescimento determinado.

Figure 3. Expression patterns and interaction of some key genes involved in the establishment of the determinate state of the shoot floral meristem. Arrows and "T"-bars represent positive and negative regulation, respectively. Solid lines represent interactions between the transcription factors for which experimental evidence is available; broken line indicates predicted interaction between these elements. LFY (LEAFY - key element for the floral identity) and WUS (WUSCHEL - crucial for the vegetative shoot identity) act together in the induction of AG (AGAMOUS) expression, whose transcription product is believed to repress WUS expression, resulting in the extinction of the stem cell niche and, consequently, the establishment of determinate growth.

com o silenciamento temporário de genes-chave na manutenção do caráter indeterminado do MAC, como os fatores de transcrição KNOX e WUS (Mayer et al. 1998, Scofield \& Murray 2006, Guo et al. 2008).

Um grande corpo de evidências dá suporte à existência de uma rede gênica complexa estabelecida para explicar a transição do MAC vegetativo para a identidade meristemática floral em A. thaliana. Segundo o modelo simplificado de sinalização neste processo de transição, os genes $L E A F Y$ (LFY), SUPPRESSOR OF OVEREXPRESSION OF
CONSTANS1 e FLOWERINGLOCUS T representam pontos de convergência e integração das diversas redes sinalizadoras necessárias à especificação da identidade do meristema floral (Lee et al. 2000, Boss et al. 2004, Corbesier et al. 2007). O gene LFY codifica um fator de transcrição que confere identidade floral ao meristema em resposta aos sinais indutores da floração, cuja função é exercida, inicialmente, pela regulação positiva da expressão de APETALAl, CAULIFLOWER e LATE MERISTEM IDENTITYI, os quais irão participar, em última análise, na diferenciação dos órgãos florais (Weigel et al. 1992, Liljegren et al. 1999, William et al. 2004, Saddic et al. 2006).

Conforme apresentado na figura 3 , a especificação do estado determinado do meristema floral depende da expressão do gene que codifica o fator de transcrição AGAMOUS (AG), pertencente à família MADS (Yanofsky et al. 1990). A expressão de $A G$ ocorre em reposta à ligação direta e conjunta de LFY e WUS nas regiões regulatórias da transcrição deste gene, sendo que o produto da transcrição de $A G$ é conhecido por reprimir a própria expressão de WUS, levando à perda da atividade das células-tronco e, conseqüentemente, proporcionando a determinação meristemática (Lohmann et al. 2001, Lenhard et al. 2001, Sablowski et al. 2007). Evidências recentes apontam para a participação de novos elementos ainda não muito bem conhecidos que regulariam a expressão de $A G$, influenciando, portanto, os demais fatores envolvidos no controle da determinação do meristema floral (Das et al. 2009).

\section{Estudos do desenvolvimento meristemático em espécies-modelo versus diversidade vegetal}

Muito de nosso conhecimento sobre as redes de sinalização que regulam o desenvolvimento vegetal, incluindo o desenvolvimento meristemático, está baseado na planta-modelo $A$. thaliana. Esta espécie foi eleita como principal modelo para estudos genéticos devido ao seu ciclo reprodutivo curto, genoma pequeno, manipulação genética simples, e facilidade de crescimento e análise das populações devido ao seu pequeno porte (Meyerowitz 1989, LevYadun \& Sederoff 2000). Como visto resumidamente nesta revisão, os estudos de genética, bioquímica, biologia molecular e biologia celular realizados prioritariamente nesta espécie têm possibilitado um avanço considerável no conhecimento sobre 
as funções gênicas nas cascatas de sinalização intracelular e intercelular que regulam importantes mecanismos do desenvolvimento vegetal.

No entanto, a extrapolação dos mecanismos moleculares descobertos em A. thaliana para as demais plantas, em parte, negligencia a filogenia vegetal altamente ramificada, cujas divergências evolutivas entre gimnospermas e angiospermas, bem como entre monocotiledôneas e eudicotiledôneas, apresentam elementos complexos em relação às distâncias evolutivas entre os diferentes grupos do ponto de vista da seleção natural. Dessa forma, a extrapolação das redes de sinalização molecular descobertas em A. thaliana para os demais vegetais depende ainda de estudos comparativos da biologia evolutiva e do desenvolvimento entre A. thaliana e as demais espécies vegetais, a fim de se distinguir princípios fundamentais daqueles que estão sujeitos à variação e seleção durante o curso da especiação (Winter et al. 2002, Chaw et al. 2004, Nardmann \& Werr 2007)

Segundo Nardmann \& Werr (2007), este tipo de abordagem traz consigo o desafio de que a origem das espécies estaria relacionada, de acordo com a teoria evolutiva de Darwin, à seleção natural (Darwin 1859), e este evento ocorreria em função do fenótipo e não no nível gênico. Desta forma, a filogenia de sequiências de DNA pode identificar o repertório gênico compartilhado pelas espécies existentes, porém, somente estudos sobre a função de certos genes, bem como a maneira pela qual eles estão integrados nas redes regulatórias do desenvolvimento, poderão fornecer informações mais precisas sobre os mecanismos que determinam certos fenótipos selecionados nas espécies.

De fato, apesar de se ter descoberto, nos últimos anos, diversos genes envolvidos na morfogênese das plantas, ainda se sabe muito pouco sobre a conservação funcional destes nos diversos grupos vegetais evolutivamente distanciados. Este tipo de conhecimento depende de análises sobre a função dos respectivos genes ortólogos em uma variedade de espécies vegetais que não se restrinjam apenas às espécies-modelo mais estudadas atualmente (DavidSchwartz \& Sinha 2007). A seleção criteriosa de espécies-chave portadoras de atributos particulares de desenvolvimento para utilização como plantasmodelo poderia auxiliar no entendimento de questões que persistem sobre os mecanismos que controlam, por exemplo, o estabelecimento, a organização, a manutenção e a determinação meristemática.
Orchidaceae representa um grupo de plantas com elevado potencial de contribuição nesta vertente, uma vez que é uma das maiores famílias entre as angiospermas, constituída de cerca de 25.000 espécies encontradas e adaptadas aos mais diferentes ambientes, com elevada diversidade de características do desenvolvimento (Mabberley 1997, Huang et al. 2008). Não por acaso, Charles Darwin pioneiramente as reconheceu como plantas extremamente apropriadas para estudos de processos evolutivos, devotando um livro inteiro para análises sobre "As várias formas pelas quais as orquídeas são fertilizadas por insetos" (Darwin 1877). Apesar dessas indicações promissoras, as orquídeas ainda continuam relativamente pouco representadas em estudos sobre especiação, evolução e isolamento reprodutivo, assim como de sinais moleculares que controlam o desenvolvimento (Peakall 2007).

Dentre os estudos conduzidos sobre a atividade meristemática em orquídeas, destacam-se aqueles realizados com espécies pertencentes ao grupo Catasetinae, mais especificamente Catasetum fimbriatum, uma planta epífita cujos meristemas, especialmente os radiculares, possuem elevado grau de complexidade e plasticidade nas respostas fisiológicas e morfológicas. Os meristemas apicais de suas raízes, por exemplo, convertem-se rapidamente em meristemas caulinares ectópicos quando isolados e incubados in vitro (Kerbauy 1984, Colli \& Kerbauy 1993), sendo que este evento peculiar foi recentemente descoberto como dependente do estágio do desenvolvimento radicular.

Conforme constatado por Rodrigues et al. (2007), a capacidade de conversão do MAR em um meristema caulinar ectópico aumenta à medida que a raiz envelhece, cessa o seu crescimento e o MAR se torna determinado. Ainda de acordo com estes autores, a parada do crescimento radicular decorre de diversas modificações estruturais, metabólicas e hormonais no MAR, as quais ocorrem de maneira gradual durante o envelhecimento radicular, proporcionando a devida competência para o estabelecimento de um meristema caulinar ectópico no MAR desta orquídea (Rodrigues et al. 2007, 2008). Sendo assim, os MARs de $C$. fimbriatum diferem dos tecidos meristemáticos da maioria das angiospermas, onde comumente observase um maior potencial regenerativo em tecidos relativamente mais jovens (Kerbauy 1999).

Com relação à atividade do MAC de C.fimbriatum, vale destacar uma correlação inversa entre o estado indeterminado deste meristema e o desenvolvimento 
dos pseudobulbos, sendo que este resulta numa inibição total das divisões celulares no ápice caulinar desta orquídea. Todavia, a atividade do MAC pode ser rapidamente retomada após a transferência das plantas para o escuro, processo este coincidente com um acúmulo acentuado de citocininas nas plantas como um todo (Suzuki et al. 2004).

Uma das dificuldades destas pesquisas é a inexistência de uma espécie-modelo de orquídea bem estudada no contex to fisiológico, genético e molecular. Esse tipo de dificuldade também é encontrado em muitas outras espécies devido, principalmente, à falta de mutantes e aos ciclos de vida longos. Todavia, alguns destes desafios podem ser minimizados com sucesso por meio da utilização de diferentes ferramentas de estudo, criatividade e persistência, além da escolha de uma espécie-alvo interessante aos propósitos da pesquisa realizada (Peakall 2007, David-Schwartz \& Sinha 2007).

Diferentes abordagens experimentais vêm sendo utilizadas para superar tais dificuldades. Entretanto, em muitos casos, os genes sob investigação não se comportam de acordo com o esperado nas vias de sinalização descritas para as principais espécies-modelo, possivelmente, devido à ocorrência de modificações nas interações entre eles, seus reguladores e/ou entre seus alvos (Doebley \& Lukens 1998, Wray et al. 2003, David-Schwartz \& Sinha 2007). Estudos com genes sabidamente importantes no desenvolvimento meristemático apresentaram importantes modificações entre as espécies até o momento analisadas, como é o caso do sistema WUS/ CLV, essencial no controle das células-tronco do MAC de A. thaliana, o qual parece ter sofrido adaptações significativas durante a especiação vegetal. Assim, a título de exemplo, em Zea mays verificou-se a existência de dois parálogos de WUS (ZmWUSI e ZmWUS2), os quais, diferentemente do observado em A. thaliana, podem também contribuir para o desenvolvimento foliar. Estes dados revelam que os padrões de expressão de WUS em gramíneas possuem adaptações distintas em relação ao modelo vegetal A. thaliana, sugerindo uma diversidade significante de mecanismos responsáveis pela especificação dos nichos de células-tronco durante a evolução das angiospermas (Nardmann \& Werr 2006, 2007).

\section{Conclusões}

Uma melhor compreensão do desenvolvimento das plantas tem sido alcançada nos últimos anos graças às pesquisas sobre os mecanismos de controle da atividade meristemática. O foco principal destes estudos tem se voltado mais especificamente aos mecanismos moleculares envolvidos no controle da capacidade das células-tronco pluripotentes tanto de manter sua própria população em nichos específicos no interior dos meristemas quanto de originar células derivadas que se diferenciarão em tecidos caulinares e radiculares. No entanto, a quase totalidade dos dados disponíveis na literatura atual tem se concentrado em descobertas provenientes de pesquisas realizadas com Arabidopsis thaliana.

Estes estudos, juntamente com outros realizados em outras poucas espécies, têm permitido um progresso considerável na compreensão sobre a maneira pela qual a organização e o funcionamento dos meristemas são mantidos e, particularmente, sobre o papel desempenhado por diversas moléculas sinalizadoras neste processo. Espera-se que, em breve, seja possível a realização de análises comparativas entre diferentes grupos vegetais sobre o grau de conservação funcional dos genes descobertos como essenciais no controle meristemático das principais plantas-modelo.

\section{Literatura citada}

Aida, M. \& Tasaka, M. 2006. Genetic control of shoot organ boundaries. Current Opinion in Plant Biology 9: $72-77$.

Aida, M., Beis, D., Heidstra, R., Willemsen, V., Blilou, I., Galinha, C., Nussaume, L., Noh, Y-S., Amasino, R. \& Scheres, B. 2004. The PLETHORA genes mediate patterning of the Arabidopsis root stem cell niche. Cell 119: 109-120.

Atta, R., Laurens, L., Boucheron-Dubuisson, E., Guivarc'h, A., Carnero, E., Giraudat-Pautot, V., Rech, P. \& Chriqui, D. 2009. Pluripotency of Arabidopsis xylem pericycle underlies shoot regeneration from root and hypocotyl explants grown in vitro. The Plant Journal 957: 626-644.

Barlow, P.W. 1997. Stem cells and founder zones in plants, particularly their roots. In: C.S. Potten (ed.). Stem Cells. Academic, London, pp. 29-57.

Barthélémy, D. \& Caraglio, Y. 2007. Plant architecture: a dynamic, multilevel and comprehensive approach to plant form, structure and ontogeny. Annals of Botany 99: 375-407.

Bauer, P., Poirier, S., Ratet, P. \& Kondorosi, A. 1997. MsEnod12A expression is linked to meristematic activity during development of indeterminate and determinate nodules and roots. Molecular Plant 10: 39-49. 
Baurle, I. \& Laux, T. 2003. Apical meristems: the plant's fountain of youth. BioEssays 25: 961-970.

Benfey, P.N., Linstead, P.J., Roberts, K., Schiefelbein, J.W., Hauser, M.-T. \& Aeschbacher, R.A. 1993. Root development in Arabidopsis: four mutants with dramatically altered root morphogenesis. Development 119: 57-70.

Benková, E. \& Hejátko, J. 2009. Hormone interactions at the root apical meristem. Plant Molecular Biology 69: 383-396.

Benková, E., Michniewicz,M.,Sauer, M., Teichmann,T., Seifertova, D., Jurgens, G. \& Friml, J. 2003, Local, efflux-dependent auxin gradients as a common module for plant organ formation. Cell 115: 591-602.

Beveridge, C.A., Mathesius, U., Rose, R.J. \& Gresshoff, P.M. 2007. Common regulatory themes in meristem development and whole-plant homeostasis. Current Opinion in Plant Biology 10: 44-51.

Birnbaum, K.D. \& Alvarado, A.S. 2008. Slicing across kingdoms: regeneration in plants and animals. Cell 132: 697-710.

Bögre, L., Magyar,Z. \& López-Juez, E. 2008. New clues to organ size control in plants. Genome Biology 9: 226.

Boss, P.K., Bastow, R.M., Mylne, J.S. \& Dean, C. 2004. Multiple pathways in the decision to flower: enabling, promoting, and resetting. The Plant Cell 16: S18-S31.

Brand, U., Fletcher, J.C., Hobe, M., Meyerowitz, E.M. \& Simon, R. 2000. Dependence of stem cell fate in Arabidopsis on a feedback loop regulated by CLV3 activity. Science 289: 617-619.

Burdon, T., Smith, A. \& Savatier, P. 2002. Signalling, cell cycle and pluripotency in embryonic stem cells. Trends in Cell Biology 12: 432-438.

Byrne, M.E., Barley, R., Curtis, M., Arroyo, J.M., Dunham, M., Hudson, A. \& Martienssen, R.A. 2000. Asymmetric leaves1 mediates leaf patterning and stem cell function in Arabidopsis. Nature 408: 967-971.

Can, A. 2008. A concise review on the classification and nomenclature of stem cells. Turk Journal of Hematology 25: 57-9.

Carraro, N., Peaucelle, A., Laufs, P. \& Traas, J. 2006. Cell differentiation and organ initiation at the shoot apical meristem. Plant Molecular Biology 60: 811-826.

Casamitjana-Martinez, E., Hofhuis, H.F., Xu, J., Liu, C.-M., Heidstra, R. \& Scheres, B. 2003. Root-specific CLE19 overexpression and the sol1/2 suppressors implicate a CVL-like pathway in the control of Arabidopsis root meristem maintenance. Current Biology 13: 1435-1441.

Chandler, J., Nardmann, J. \& Werr, W. 2008. Plant development revolves around axes. Trends in Plant Science 13: 78-84.
Chaw, S.M., Chang, C.C., Chen, H.L.\& Li, W.H. 2004. Dating the monocot - dicot divergence and the origin of core eudicots using whole chloroplast genomes. Journal of Molecular Evolution 58: 424-441.

Clark, S.E., Jacobsen, S.E., Levin, J.Z. \& Meyerowitz, E.M. 1996. The CLAVATA and SHOOT MERISTEMLESS loci competitively regulate meristem activity in Arabidopsis. Development 122: 1567-1575.

Cline, M.G. 1991. Apical dominance. Botanical Review 57: 318.

Colli, S. \& Kerbauy, G.B. 1993. Direct root-tip conversion of Catasetum fimbriatum into protocorm-like bodies. Effects of auxin and cytokinin. Plant Cell, Tissue and Organ Culture 33: 39-44.

Corbesier, L., Vincent, C., Jang, S., Fornara, F., Fan, Q., Searle, I., Giakountis, A., Farrona, S., Gissot, L., Turnbull, C. \& Coupland, G. 2007. FT protein movement contributes to long-distance signaling in floral induction of Arabidopis. Science 316: 1030-1033.

Cui, H., Levesque, M.P., Vernoux, T., Jung, J.W., Paquette, A.J., Gallagher, K.L., Wang, J.Y., Blilou, I., Scheres, B. \& Benfey, P.N. 2007. An evolutionarily conserved mechanism delimiting SHR movement defines a single layer of endodermis in plants. Science 316: 421-425.

D'Amato, F. 1978. Chromosome number variation in cultured cells and regenerated plants. In: T.A. Thorpe (ed.). Frontiers of plant tissue culture. University of Calgary Press, Calgary, pp. 287-295.

Darwin, C. 1859. On the origin of species by means of natural selection or the preservation of favored races in the struggle for life. Murray J., London.

Darwin, C. 1877. The various contrivances by which orchids are fertilized by insects (1984ed). University of Chicago Press, Chicago.

Das, P., Ito, T., Wellmer, F., Vernoux, T., Dedieu, A., Traas, J. \& Meyerowitz, E.M. 2009. Floral stem cell termination involves the direct regulation of AGAMOUS by PERIANTHIA. Development 136: 1605-1611.

David-Schwartz, R. \& Sinha, N. 2007. Evolution and development in plants: bridging the gap. International Journal of Plant Sciences 168: 49-59.

de Reuille, P.B., Bohn-Courseau, I., Ljung, K., Morin, H., Carraro, N., Godin, C.\& Traas, J. 2006. Computer simulations reveal properties of the cell-cell signaling network at the shoot apex in Arabidopsis. Proceedings of the National Academy of Sciences of the United States of America 103: 1627-1632.

De Smet, I., Vanneste, S., Inzé, D. \& Beeckman, T. 2006. Lateral root initiation or the birth of a new meristem. Plant Molecular Biology 60: 871-88.

Dello-Ioio, R., Linhares, F.S., Scacchi, E., CasamitjanaMartinez, E., Heidstra, R., Costantino, P. \& Sabatini, S. 2007. Cytokinins determine Arabidopsis root- 
meristem size by controlling cell differentiation. Current Biology 17: 678-682.

Dello-Ioio, R.D., Nakamura, K., Moubayidin, L., Perilli, S., Taniguchi, M., Morita, M.T., Aoyama, T., Costantino, P. \& Sabatini, S. 2008. A genetic framework for the control of cell division and differentiation in the root meristem. Science 322: 1380-1384.

DiDonato, R.J., Arbuckle, E., Buker, S., Sheets, J., Tobar, J., Totong, R., Grisafi, P., Fink, G.R. \& Celenza, J.L. 2004. Arabidopsis ALF4 encodes a nuclear-localized protein required for lateral root formation. Plant Journal 37: 340-353.

Di Laurenzio, L., Wysocka-Diller, J., Malamy, J.E., Pysh, L., Helariutta, Y., Freshour, G., Hahn, M.G., Feldmann, K.A. \& Benfey, P.N. 1996. The SCARECROW gene regulates an asymmetric cell division that is essential for generating the radial organization of the Arabidopsis root. Cell 86: 423-433.

Dinneny, J.R. \& Benfey, P.N. 2008. Plant stem cell niches: standing the test of time. Cell 132: 553-557.

Doebley, J. \& Lukens, L. 1998. Transcriptional regulators and the evolution of plant form. Plant Cell 10: 10751082.

Dubois, T., Guedira, M., Dubois, J. \& Vasseur, J. 1990. Direct somatic embryogenesis in roots of Cichorium: as callose an early marker? Annals of Botany 65: 539-545.

Dubrovsky, J.G., Rost, T.L., Colon-Carmona, A. \& Doerner, P. 2001. Early primordium morphogenesis during lateral root initiation in Arabidopsis thaliana. Planta 214: 30-36.

Dubrovsky, J.G., Sauer, M., Napsucialy-Mendivil, S., Ivanchenko, M.G., Friml, J., Shishkova, S., Celenza, J. \& Benková, E. 2008. Auxin acts as a local morphogenetic trigger to specify lateral root founder cells. Proceedings of the National Academy of Sciences of the United States of America 105: 8790-8794.

Endrizzi, K., Moussian, B., Haecker, A., Levin, J.Z. \& Laux, T. 1996. The SHOOT MERISTEMLESS gene is required for maintenance of undifferentiated cells in Arabidopsis shoot and floral meristems and acts at a different regulatory level than the meristem genes WUSCHEL and ZWILLE. Plant Journal 10: 967-979.

Fehér, A., Pasternak, T.P. \& Dudits, D. 2003. Transition of somatic plant cells to an embryogenic state. Plant Cell Tissue and Organ Culture 74: 201.

Fiers, M., Ku, K.L. \& Liu, C-M. 2007. CLE peptide ligands and their roles in establishing meristems. Current Opinion in Plant Biology 10: 39-43.

Friml, J., Benfey, P., Benková, E., Bennett, M., Berleth, T., Geldner, N., Grebe, M., Heisler, M., Hejátko, J., Jürgens, G., Laux, T., Lindsey, K., Lukowitz, W., Luschnig, C., Offringa, R., Scheres, B., Swarup, R., Torres-Ruiz, R., Weijers, D. \& Zažímalová, E. 2006.
Apical-basal polarity: why plants cells don't stand on their heads. Trends in Plant Science 11: 12-14.

Friml, J., Yang, X., Michniewicz, M., Weijers, D., Quint, A., Tietz, O., Benjamins, R., Ouwerkerk, P.B., Ljung, K., Sandberg, G., Hooykaas, P.J., Palme, K. \& Offringa, R. 2004. A PINOID dependent binary switch in apical-basal PIN polar targeting directs auxin efflux. Science 306: 862-865.

Fukaki, H., Okushima, Y. \& Tasaka, M. 2007. Auxinmediated lateral root formation in higher plants. International Review of Cytology - a Survey of Cell Biology 256: 111-137.

Furutani, M., Vernoux, T., Traas, J., Kato, T., Tasaka,M. \& Aida, M. 2004. PINFORMED1 and PINOID regulate boundary formation and cotyledon development in Arabidopsis embryogenesis. Development 131: 50215030 .

Galinha, C., Hofhuis, H., Luijten, M., Willemsen, V., Blilou, I., Heidstra, R. \& Scheres, B. 2007. PLETHORA proteins as dose-dependent master regulators of Arabidopsis root development. Nature 449: 1053-1057.

Gehring, W.J. 1987. Homeoboxes in the study of development. Science 236: 1245-1252.

Gisel, A., Barella, S., Hempel, F.D. \& Zambryski, P.C. 1999. Temporal and spatial regulation of symplastic trafficking during development in Arabidopsis thaliana apices. Development 126: 1879-1889.

Gómez-Mena, C. \& Sablowski, R. 2008. Arabidopsis thaliana HOMEOBOX GENE1 establishes the basal boundaries of shoot organs and controls stem growth. The Plant Cell 20: 2059-2072.

Green, K.A., Prigge, M.J., Katzman, R.B.\& Clark, S.E. 2005. CORONA, a member of the class III homeodomain leucine zipper gene family in Arabidopsis, regulates stem cell specification and organogenesis. Plant Cell 17: 691-704.

Grieneisen, V.A., Xu, J., Maree, A.F., Hogeweg, P. \& Scheres, B. 2007. Auxin transport is sufficient to generate a maximum and gradient guiding root growth. Nature 449: 1008-1013.

Guilfoyle, T.J., Ulmasov, T. \& Hagen, G. 1998. The ARF family of transcription factors and their role in plant hormone-responsive transcription. Cellular and Molecular Life Sciences 54: 619-627.

Guo, M., Thomas, J., Collins, G. \& Timmermans, M.C.P. 2008. Direct repression of KNOX loci by the ASYMMETRIC LEAVES1 complex of Arabidopsis. The Plant Cell 20: 48-58.

Guyomarc'h, S., Bertrand, C., Delarue., M. \& Zhou, D-X.2005. Regulation of meristem activity by chromatin remodeling. Trends in Plant Science. 10: 332-338.

Haberlandt, G. 1902. Culturversuche mit isolierten. Pflanzenzellen. Sitzungsberichte der Kaiserlichen. 
Akademie der Wissenschaften. MathematischNaturwiss. K1, Abt I, 69-92.

Haecker, A., Gross-Hardt, R., Geiges, B., Sarkar, A., Breuninger, H., Herrmann, M. \& Laux, T. 2004. Expression dynamics of WOX genes mark cell fate decisions during early embryonic patterning in Arabidopsis thaliana. Development 131: 657-668.

Hardtke, C.S. \& Berleth, T. 1998. The Arabidopsis gene MONOPTEROS encodes a transcription factor mediating embryo axis formation and vascular development. Embo Journal 17: 1405-1411.

Heidstra, R., Welch, D. \& Scheres, B. 2004. Mosaic analyses using marked activation and deletion clones dissect Arabidopsis SCARECROW action in asymmetric cell division. Genes \& Development 18: 1964-1969.

Heisler, M. \& Jönsson, H. 2007. Modelling meristem development in plants. Current Opinion in Plant Biology 10: 92-97.

Heisler, M.G., Ohno, C., Das P., Sieber, P., Reddy, G.V., Long, J.A. \& Meyerowitz, E.M. 2005. Patterns of auxin transport and gene expression during primordium development revealed by live imaging of the Arabidopsis inflorescence meristem. Current Biology 15: 1899-1911.

Helariutta,Y., Fukaki, H., Wysocka-Diller, J., Nakajima, K., Jung, J., Sena, G., Hauser, M.-T. \& Benfey, P.N. 2000. The SHORT-ROOT gene controls radial patterning of the Arabidopsis root through radial signaling. Cell 101: 555-567.

Himmelbach, A., Hoffmann, T., Leube, M., Hohener, B. \& Grill, E. 2002. Homeodomain protein ATHB6 is a target of the protein phosphatase ABI1 and regulates hormone responses in Arabidopsis. Embo Journal 21: 3029-3038.

Hirsch, A.M. 1992. Developmental biology of legume nodulation. New Phytologist 122: 211-237.

Hoxtermann, E. 1997. Cellular 'elementary organisms' in vitro. The early vision of Gottlieb Haberlandt and its realization. Physiologia Plantarum 100: 716-728.

Huang, B-Q., Yang, X.-Q., Yu, F.-H., Luo, Y.-B. \& Tai, Y.-D. 2008. Surprisingly high orchid diversity in travertine and forest areas in the Huanglong valley, China, and implications for conservation. Biodiversity and Conservation 17: 2773-2786.

Irish, V.F. 2008. The Arabidopsis petal: a model for plant organogenesis. Trends in Plant Science 13: 430-436.

Ivanov, V.B. 2004. Meristem as a self-renewing system: maintenance and cessation of cell proliferation (a review). Russian Journal of Plant Physiology 51: 834-847.

Jasinski, S., Piazza, P., Craft, J., Hay, A., Woolley, L., Rieu, I., Phillips, A., Hedden, P. \& Tsiantis, M. 2005. KNOX action in Arabidopsis is mediated by coordinate regulation of cytokinin and gibberellin activities. Current Biology 15: 1560-1565.
Jiang, K. \& Feldman, L.J. 2005. Regulation of root apical meristem development. Annual Review of Cell Developmental Biology 21: 485-509.

Jiang, K., Meng, Y.L. \& Feldman, L.J. 2003. Quiescent center formation in maize roots is associated with an auxin-regulated oxidizing environment. Development 130: 1429-1438.

Jonsson, H., Heisler, M.G., Shapiro, B.E., Meyerowitz, E.M.\& Mjolsness, E. 2006. An auxin-driven polarized transport model for phyllotaxis. Proceedings of the National Academy of Sciences of the United States of America 103: 1633-1638.

Kamiya, N., Nagasaki, H., Morikami, A., Sato, Y. \& Matsuoka, M. 2003. Isolation and characterization of a rice WUSCHEL-type homeobox gene that is specifically expressed in the central cells of a quiescent center in the root apical meristem. Plant Journal 35: 429-441.

Kanrar, S., Bhattacharya, M., Arthur, B., Courtier, J. \& Smith, H.M.S. 2008. Regulatory networks that function to specify flower meristems require the function of homeobox genes PENNYWISE and POUND-FOOLISH in Arabidopsis. The Plant Journal 54: 924-937.

Keller, T., Abbott, J., Moritz, T. \& Doerner, P. 2006. Arabidopsis REGULATOR OF AXILLARY MERISTEMS1 controls a leaf axil stem cell niche and modulates vegetative development. Plant Cell 18: 598-611.

Kepinski, S. 2006. Integrating hormone signaling and patterning mechanisms in plant development. Current Opinion in Plant Biology 9: 28-34.

Kerbauy, G.B. 1984. Regeneration of protocorm-like bodies through in vitro culture of roots tips of Catasetum (Orchidaceae). Journal of Plant Physiology 113: 287-291.

Kerbauy, G.B. 1999. Competência e determinação celular em cultura de células e tecidos de plantas. In: A.C. Torres, L.S. Caldas \& J.A. Buso (eds). Cultura de tecidos e transformação genética de plantas. v. 2. Embrapa, Brasília, pp. 519-531.

Kerk, N. \& Feldman, L. 1995. A biochemical model for the initiation and maintenance of the quiescent center: implications for organization of root meristem. Development 121: 2825-2833.

Knoblich, J.A. 2008. Mechanisms of asymmetric stem cell division. Cell 132: 583-597.

Kurata, T., Okada, K. \& Wada, T. 2005. Intercellular movement of transcription factors. Current Opinion in Plant Biology 8: 600-605.

Kyozuka, K. 2007. Control of shoot and root meristem function by cytokinin. Current Opinion in Plant Biology 10: 442-446.

Laux, T. 2003. The stem cell concept in plants: a matter of debate. Cell 113: 281-283.

Laux, T., Mayer, K.F., Berger, J. \& Jürgens, G. 1996. The WUSCHEL gene is required for shoot and floral meristem integrity in Arabidopsis. Development 122: 87-96. 
Lee, H., Suh, S.S., Park, E., Cho, E., Ahn, J.H., Kim, S.-G., Lee, J.S., Kwon, Y.M. \& Lee, I. 2000. The AGAMOUS-LIKE 20 MADS domain protein integrates floral inductive pathways in Arabidopsis. Genes \& Development 14: 2366-2376.

Leibfried, A., To, J.P., Busch, W., Stehling, S., Kehle, A., Demar, M., Kieber, J.J. \& Lohmann, J.U. 2005. WUSCHEL controls meristem function by direct regulation of cytokinin-inducible response regulators. Nature 438: 1172-1175.

Lenhard, M., Bohnert, A., Jurgens, G. \& Laux, T. 2001. Termination of stem cell maintenance in Arabidopsis floral meristems by interactions between WUSCHEL and AGAMOUS. Cell 105: 805-814.

Lenhard, M., Jürgens, G. \& Laux, T. 2002. The WUSCHEL and SHOOTMERISTEMLESS genes fulfill complementary roles in Arabidopsis shoot meristem regulation. Development 129: 3195-3206.

Levesque, M.P., Vernoux, T., Busch, W., Cui, H., Wang, J.Y., Blilou, I., Hassan, H., Nakajima, K., Matsumoto, N., Lohmann, J.U., Scheres, B. \& Benfey, P.N. 2006. Whole-genome analysis of the SHORT-ROOT developmental pathway in Arabidopsis. PLoS Biology 4: 739-752.

Lev-Yadun, S. \& Sederoff, R. 2000. Pines as model gymnosperms to study evolution, wood formation, and perennial growth. Journal of Plant Growth Regulation 19: 290-305.

Liljegren, S.J., Gustafason-Brown, C., Pinyopich, A., Ditta, G.S. \& Yanofsky, M.F. 1999. Interactions among APETALA1, LEAFY, and TERMINAL FLOWER 1 specify meristem fate. Plant Cell 11: 1007-1018.

Lincoln, C., Long, J., Yamaguchi, J., Serikawa, K. \& Hake, S. 1994. A knotted1-like homeobox gene in Arabidopsis is expressed in the vegetative meristem and dramatically alters leaf morphology when overexpressed in transgenic plants. Plant Cell 6: 1859-1876.

Lohmann, J.U., Hong, R.L., Hobe, M., Busch, M.A., Parcy, F., Simon, R. \& Weigel, D. 2001. A molecular link between stem cell regulation and floral patterning in Arabidopsis. Cell 105: 793-803.

Lohmann, J.U.\& Weigel, D. 2002. Building beauty: the genetic control of floral patterning. Developmental Cell 2: $135-142$.

Long, J. \& Barton, M.K. 2000. Initiation of axillary and floral meristems in Arabidopsis. Developmental Biology 218: 341-353.

Long, J.A., Moan, E.I., Medford, J.I. \& Barton, M.K. 1996. A member of the KNOTTED class of homeodomain proteins encoded by the STM gene of Arabidopsis. Nature 379: 66-69.
Lucas, W.J., \& Lee, J.Y. 2004. Plasmodesmata as a supracellular control network in plants. Nature Reviews Molecular Cell Biology 5: 712-726.

Mabberley, D.J. 1997. The plant book. 2 ed. Cambridge University Press, Cambridge.

Magyar, Z., De Veylder, L., Atanassova, A., Bako, L., Inze, D. \& Bögre, L. 2005. The role of the Arabidopsis E2FB transcription factor in regulating auxin-dependent cell division. Plant Cell 17: 2527-2541.

Mathesius, U. 2008. Auxin: at the root of nodule development? Functional Plant Biology 35: 651-668.

Maughan, S.C., Murray, J.A.H. \& Bögre, L. 2006. A greenprint for growth: signalling the pattern of proliferation. Current Opinion in Plant Biology 9: 490-495.

Mayer, K.F., Schoof, H., Haecker, A., Lenhard, M., Jürgens, G. \& Laux, T. 1998. Role of WUSCHEL in regulating stem cell fate in the Arabidopsis shoot meristem. Cell 95: 805-815.

McSteen, P. \& Leyser, H.M.O. 2005. Shoot branching. Annual Review of Plant Biology 56: 353-374.

Meyerowitz, E.M. 1989. Arabidopsis, a useful weed. Cell 56: 263-269.

Miwa, H., Kinoshita, A., Fukuda, H. \& Sawa, S. 2009. Plant meristems: CLAVATA3/ESR-related signaling in the shoot apical meristem and the root apical meristem. Journal of Plant Research 122: 31-39.

Nakajima, K., Sean, G., Nawy, T. \& Benfey, P.N. 2001. Intercellular movement of the putative transcription factor SHR in root patterning. Nature 413: 307-311.

Nardmann, J. \& Werr, W. 2006. The shoot stem cell niche in angiosperms: expression patterns of WUS orthologues in rice and maize imply major modifications in the course of mono and dicot evolution. Molecular Biology and Evolution 23: 2492-2504.

Nardmann, J. \& Werr, W. 2007. The evolution of plant regulatory networks: what Arabidopsis cannot say for itself. Current Opinion in Plant Biology 10: 653-659.

Oldroyd, G.E.D. \& Downie, J.A. 2008. Coordinating nodule morphogenesis with rhizobial infection in legumes. Annual Review of Plant Biology 59: 519-46.

Ongaro, V. \& Leyser, O. 2008. Hormonal control of shoot branching. Journal of Experimental Botany 59: 67-74.

Ongaro, V., Bainbridge, K., Williamson, L. \& Leyser, O. 2008. Interactions between axillary branches of Arabidopsis. Molecular Plant 1: 388-400.

Orkin,S.H.2000. Diversification of hematopoietic stem cells to specific lineages. Nature Reviews Genetics 1: 57-64.

Parizot, B., Laplaze, L., Ricaud, L., BoucheronDubuisson, E., Bayle, V., Bonke, M., De Smet, I., Poethig, S.R., Helariutta, Y., Haseloff, J., Chriqui, D., Beeckman, T. \& Nussaume, L. 2007. Diarch 
symmetry of the vascular bundle in Arabidopsis root encompasses the pericycle and is reflected in distich lateral root initiation. Plant Physiology 146: 140-148.

Peakall, R. 2007. Speciation in the Orchidaceae: confronting the challenges. Molecular Ecology 16: 2834-2837.

Peterson, R.L. 1975. The initiation and development of roots buds. In: J.G. Torrey \& D.T. Clarkson (eds). The development and function of roots. Academic Press, New York, pp. 125-161.

Potten, C.S. \& Loeffler, M. 1997. Stem cells and cellular pedigrees - a conceptual introduction. In: C.S. Potten (ed.) Stem Cells. Academic, London, pp. 1-27.

Rast, M.I. \& Simon, R. 2008. The meristem-to-organ boundary: more than an extremity of anything. Current Opinion in Genetics \& Development 18: 287-294.

Reddy, G.V. 2008. Live-imaging stem-cell homeostasis in the Arabidopsis shoot apex. Current Opinion in Plant Biology 11: 88-93.

Reinhardt, D., Mandel, T. \& Kuhlemeier, C.2000. Auxin regulates the initiation and radial position of plant lateral organs. Plant Cell 12: 507-518.

Reinhardt, D., Pesce, E.R., Stieger, P., Mandel, T., Baltensperger, K., Bennett, M., Traas, J., Friml, J. \& Kuhlemeier, C. 2003. Regulation of phyllotaxis by polar auxin transport. Nature 426: 255-260.

Riechmann, J.L., Heard, J., Martin, G., Reuber, L., Jiang, C., Keddie, J., Adam, L., Pineda, O., Ratcliffe, O.J., Samaha, R.R., Creelman, R., Pilgrim, M., Broun, P., Zhang, J.Z., Ghandehari, D., Sherman, B.K.\& Yu, G. 2000. Arabidopsis transcription factors: genome-wide comparative analysis among eukaryotes. Science 290: 2105-2110.

Rodrigues, M.A., Freschi, L. \& Kerbauy, G.B. 2007. Effects of auxin transport on competence acquisition to root apical meristem conversion of Catasetum fimbriatum into buds. In Vitro Cellular \& Developmental Biology 43: S49.

Rodrigues, M.A., Freschi, L.\& Kerbauy, G.B . 2008. Nitrogen depletion is related to competence acquisition to root-to-shoot conversion in. Cellular \& Developmental Biology 44: S77.

Roudier, F., Fedorova, E., Lebris, M., Lecomte, P., Györgyey, J., Vaubert, D., Horvath, G., Abad, P., Kondorosi, A. \& Kondorosi, E. 2003. The Medicago species A2-type cyclin is auxin regulated and involved in meristem formation but dispensable for endoreduplication-associated developmental programs. Plant Physiology 131: 1091-1103.

Sabatini, S., Heidstra, R., Wildwater, M., \& Scheres, B. 2003. SCARECROW is involved in positioning the stem cell niche in the Arabidopsis root meristem. Genes \& Development 17: 354-358.

Sablowski, R. 2004. Plant and animal stem cells: conceptually similar, molecularly distinct? Trends in Cell Biology 14: 605-611.

Sablowski, R. 2007. Flowering and determinacy in Arabidopsis. Journal of Experimental Botany 58: 899-907.

Saddic, L.A., Huvermann, B., Bezhani, S., Su, Y., Winter, C.M., Kwon, C.S., Collum, R.P. \& Wagner, D. 2006. The LEAFY target LMI1 is a meristem identity regulator and acts together with LEAFY to regulate expression of CAULIFLOWER. Development 133: 1673-1682.

Sakamoto, T., Kamiya, N., Ueguchi-Tanaka, M., Iwahori, S. \& Matsuoka, M. 2001a. KNOX homeodomain protein directly suppresses the expression of a gibberellin biosynthetic gene in the tobacco shoot apical meristem. Genes \& Development 15: 581-590.

Sakamoto, T., Kobayashi, M., Itoh, H., Tagiri, A., Kayano, T., Tanaka, H., Iwahori, S. \& Matsuoka, M.2001b.Expression of a GIBBERELLIN 2-OXIDASE gene around the shoot apex is related to phase transition in rice. Plant Physiology 125: 1508-1516.

Sarkar, A.K., Luijten, M., Miyashima, S., Lenhard, M., Hashimoto, T., Nakajima, K., Scheres, B., Heidstra, R. \& Laux, T. 2007. Conserved factors regulate signalling in Arabidopsis thaliana shoot and root stem cell organizers. Nature 446: 811-814.

Scheres, B. 2007. Stem-cell niches: nursery rhymes across kingdoms. Nature Reviews Molecular Cell Biology 8: 345-354.

Scheres, B., Di Laurenzio, L., Willemsen, V., Hauser, M.T., Janmaat, K., Weisbeek, P. \& Benfey, P.N. 1995. Mutations affecting the radial organization of the Arabidopsis root display specific defects throughout the embryonic axis. Development 121: 53-62.

Schmidt, A. 1924. Histologische studien an phanerogamen vegetationspunkten. Botanisches Archive 8: 345-404.

Schmitz, G. \& Theres, K. 2005. Shoot and inflorescence branching. Current Opinion in Plant Biology 8: 506-511.

Schoof, H., Lenhard, M., Haecker, A., Mayer, K.F.X., Jürgens, G. \& Laux, T. 2000. The stem cell population of Arabidopsis shoot meristems is maintained by a regulatory loop between the CLAVATA and WUSCHEL genes. Cell 100: 635-644.

Scofield, S. \& Murray, J.A.H. 2006. The evolving concept of the meristem. Plant Molecular Biology 60: v-vii.

Sena, G., Jung, J.W. \& Benfey, P.N. 2004. A broad competence to respond to SHORT ROOT revealed by tissue-specific ectopic expression. Development 131: 2817-2826. 
Shani, E., Yanai, O.\& Ori, N. 2006. The role of hormones in shoot apical meristem function. Current Opinion in Plant Biology 9: 1-6.

Shimada, Y., Goda, H., Nakamura, A., Takatsuto, S., Fujioka, S. \& Yoshida, S. 2003. Organ-specific expression of brassinosteroid-biosynthetic genes and distribution of endogenous brassinosteroids in Arabidopsis. Plant Physiology 131: 287-297.

Shishkova, S., Rost, T.L. \& Dubrovsky, J.G. 2008. Determinate root growth and meristem maintenance in Angiosperms. Annals of Botany 101: 319-340.

Simons, J.L., Napoli, C.A., Janssen, B.J., Plummer, K.M. \& Snowden, K.C. 2007. Analysis of the DECREASED APICAL DOMINANCE genes of petunia in the control of axillary branching. Plant Physiology 143: 697-706.

Singh, M.B. \& Bhalla, P.L. 2006. Plant stem cells carve their own niche. Trends in Plant Science 11: 241-246.

Srivastava, L.M. 2002. Special Features of Plant Development. In: L.M. Srivastava (eds.). Plant growth and development - Hormones and environment. Academic Press, New York, pp. 3-22.

Stahl, Y. \& Simon, R. 2005. Plant stem cell niches. International Journal of Developmental Biology 49: 479-489.

Steeves, T.A. 2006. The shoot apical meristem: an historical perspective. Canadian Journal of Botany 84: 1629-1633.

Steward, F.C., Mapes, M.O. \& Mears, K. 1958. Growth and organized development of cultured cells. II. Organization in cultures grown from freely suspended cells. American Journal of Botany 45: 705-708.

Stewart, R. \& Dermen, H. 1970. Determination of number and mitotic activity of shoot apical initial cells by analysis of mericlinal chimeras. American Journal of Botany 57: 816-26.

Sussex, I. 2006. Plant meristems: an historical overview. In: L. Taiz \& E. Zeigler. Plant Physiology, 4 ed. Sinauer Associates, Sunderland.

Suzuki, R.M., Kerbauy, G.B. \& Zaffari, G.R. 2004. Endogenous hormonal levels and growth of darkincubated shoots of Catasetum fimbriatum. Journal of Plant Physiology 161: 929-935.

Swaminathan, K., Peterson, K. \& Jack, J. 2008. The plant B3 superfamily. Trends in Plant Science 13: 647-655.

Tucker, M.R. \& Laux, T. 2007. Connecting the paths in plant stem cell regulation. Trends in Cell Biology 17: 403-410.

van den Berg, C., Willemsen, V., Hendriks, G., Weisbeek, P. \& Scheres, B. 1997. Short-range control of cell differentiation in the Arabidopsis root meristem. Nature 390: 287-289.
Veit, B. 2009. Hormone mediated regulation of the shoot apical meristem. Plant Molecular Biology 69: 397-408.

Verdeil, J.L., Hocher, V., Huet, C., Grosdemange, F., Escoute, J., Ferrière, N. \& Nicole, M. 2001. Ultrastructural changes in coconut calli associated with the acquisition of embryogenic competence. Annals of Botany 88: 9-18.

Verdeil, J-L,Aemanno, L., Niemenak, N. \& Tranbarger, T.J.2007. Pluripotent versus totipotent plant stem cells: dependence versus autonomy? Trends in Plant Science 12: 245-252.

Vernié, T., Moreau, S., de Billy, F., Plet, J., Combier, J.-P., Rogers, C., Oldroyd, G., Frugier, F., Niebel, A. \& Gamas, P. 2008. EFD is an ERF transcription factor involved in the control of nodule number and differentiation in Medicago truncatula. The Plant Cell 20: 2696-2713.

Vernoux, T. \& Benfey, P.N. 2005. Signals that regulate stem cell activity during plant development. Current Opinion in Genetics \& Development 15: 388-394.

Vidaurre, D.P., Ploense, S., Krogan, N.T. \& Berleth, T. 2007. AMP1 and MP antagonistically regulate embryo and meristem development in Arabidopsis. Development 134: 2561-2567.

Vogel, G. 2005. How does a single somatic cell become a whole plant? Science 309: 86.

Vroemen, C.W., Mordhorst, A.P., Albrecht, C., Kwaaitaal, M.A. \& de Vries, S.C. 2003. The CUPSHAPED COTYLEDON3 gene is required for boundary and shoot meristem formation in Arabidopsis. Plant Cell 15: 1563-1577.

Wang, Y. \& Li, J. 2008. Molecular basis of plant architecture. Annual Review of Plant Biology 59: 253-279.

Weigel, D., Alvarez, J., Smyth, D.R., Yanofsky, M.F. \& Meyerowitz, E.M. 1992. LEAFY controls flower meristem identity in Arabidopsis. Cell 69: 843-859.

Weigel,D.\& Jürgens, G. 2002. Stem cells that make stems. Nature 415: 751-754.

Weijers, D., Sauer, M., Meurette, O., Friml, J., Ljung, K., Sandberg, G., Hooykaas, P. \& Offringa, R. 2005. Maintenance of embryonic auxin distribution for apicalbasal patterning by PIN-FORMED-dependent auxin transport in Arabidopsis. Plant Cell 17: 2517-2526.

William, D.A., Su, Y., Smith, M.R., Lu, M., Baldwin, D.A. \& Wagner, D. 2004. Genomic identification of direct target genes of LEAFY. Proceedings of the National Academy of Sciences of the United States of America 101: 1775-1780.

Williams, L. \& Fletcher, J.C. 2005. Stem cell regulation in the Arabidopsis shoot apical meristem. Current Opinion in Plant Biology 8: 582-586. 
Winter, K.U., Weiser, C., Kaufmann, K., Bohne, A., Kirchner, C., Kanno, A., Saedler, H. \& Theissen, G. 2002. Evolution of class B floral homeotic proteins: obligate heterodimerization originated from homodimerization. Molecular Biology and Evolution 19: 587-596.

Wray, G.A., Hahn, M.W., Abouheif, E., Balhoff, J.P., Pizer, M., Rockman, M.V.\& Romano,L.A. 2003. The evolution of transcriptional regulation in eukaryotes. Molecular Biology and Evolution 20: 1377-1419.

Xiong, Y., Liu, T., Tian, C., Sun, S., Li, J. \& Chen M. 2005. Transcription factors in rice: a genome-wide comparative analysis between monocots and eudicots. Plant Molecular Biology 59: 191-203.

Yanofsky, M.F., Ma, J.J., Bowman, J.L., Drews, G.N., Feldman, K.A. \& Meyerowitz,E.M. 1990. The protein encoded by the Arabidopsis homeotic gene agamous resembles transcription factors. Nature 346: 35-39.

Zhuravlev, Y.N. \& Omelko, A.M. 2008. Plant morphogenesis in vitro. Russian Journal of Plant Physiology 55: 579-596.

Zik, M. \& Irish, V.F. 2003. Flower development: Initiation, differentiation, and diversification. Annual Review of Cell Developmental Biology 19: 119-140. 